\title{
Medium Chain Carboxylic Acids from Complex Organic Feedstocks by Mixed Culture Fermentation
}

\author{
Vicky De Groof ${ }^{1,2}$, Marta Coma ${ }^{3}$ (D) Tom Arnot ${ }^{2,4}$, David J Leak ${ }^{3,5}$ and Ana B Lanham 2,4,* \\ 1 EPSRC Centre for Doctoral Training in Sustainable Chemical Technologies, University of Bath, \\ Claverton Down, Bath BA2 7AY, UK; V.De.Groof@bath.ac.uk \\ 2 Department of Chemical Engineering, University of Bath, Claverton Down, Bath BA2 7AY, UK; \\ T.C.Arnot@bath.ac.uk \\ 3 Centre for Sustainable Chemical Technologies (CSCT), University of Bath, Claverton Down, Bath BA2 7AY, \\ UK; M.Coma@bath.ac.uk (M.C.); D.J.Leak@bath.ac.uk (D.J.L.) \\ 4 Water Innovation \& Research Centre (WIRC), University of Bath, Claverton Down, Bath BA2 7AY, UK \\ 5 Department of Biology \& Biochemistry, University of Bath, Claverton Down, Bath BA2 7AY, UK \\ * Correspondence: a.lanham@bath.ac.uk; Tel.: +44-1225-384544
}

Academic Editor: Afroditi Chatzifragkou

Received: 30 November 2018; Accepted: 18 January 2019; Published: 22 January 2019

\begin{abstract}
Environmental pressures caused by population growth and consumerism require the development of resource recovery from waste, hence a circular economy approach. The production of chemicals and fuels from organic waste using mixed microbial cultures (MMC) has become promising. MMC use the synergy of bio-catalytic activities from different microorganisms to transform complex organic feedstock, such as by-products from food production and food waste. In the absence of oxygen, the feedstock can be converted into biogas through the established anaerobic digestion (AD) approach. The potential of MMC has shifted to production of intermediate AD compounds as precursors for renewable chemicals. A particular set of anaerobic pathways in MMC fermentation, known as chain elongation, can occur under specific conditions producing medium chain carboxylic acids (MCCAs) with higher value than biogas and broader applicability. This review introduces the chain elongation pathway and other bio-reactions occurring during MMC fermentation. We present an overview of the complex feedstocks used, and pinpoint the main operational parameters for MCCAs production such as temperature, $\mathrm{pH}$, loading rates, inoculum, head space composition, and reactor design. The review evaluates the key findings of MCCA production using MMC, and concludes by identifying critical research targets to drive forward this promising technology as a valorisation method for complex organic waste.
\end{abstract}

Keywords: anaerobic; carboxylate platform; chain elongation; circular economy; mixed microbial culture; medium chain carboxylic acid; organic waste; resource recovery; waste valorisation

\section{Introduction}

In 2016 nearly $58 \%$ of the organic fraction of municipal solid waste (OFMSW) in the EU was sent directly to landfill or incineration (estimated using the Eurostat database accessed 28/11/2018: recycling of bio-waste (cei_wm030), generation of waste by waste category (ten00108) and population on 1 January (tps00001)), resulting in undesirable environmental effects, little to no value recovery, and hence a loss of resources. However, recycling in the EU is now increasing [1], and hence separately collected organic waste is becoming more available for resource recovery or waste valorisation, i.e., the process of converting waste into energy, chemicals or materials. Technologies for bio-waste valorisation can be categorised as thermal or thermochemical such as hydrothermal liquefaction, pyrolysis and gasification, physicochemical like extraction and transesterification or biological 
conversion processes [2,3]. Biomass gasification has been proposed to homogenise various substrates to syngas and further process this for chemical production [4]. Reviews are available regarding technologies for waste to energy [5,6], or waste to chemicals and materials [7-10]. The choice of treatment method will depend on several factors such as type and availability of organic waste streams, e.g., the waste's organic strength measured by chemical oxygen demand (COD) [11], relative content of biopolymers (i.e., cellulose, hemicellulose or lignin) [12], or biomass type (woody biomass, types of agricultural residues, household organic waste and sewage sludge) $[13,14]$. Development of a circular economy where waste is used as resource for renewable energy and chemicals will require the integration of different types of conversion processes to deal with the complexity of bio-waste and maximize resource recovery [15].

Established bio-waste valorisation technologies are composting and anaerobic digestion (AD), which each produce fertilizer and methane-rich biogas as end-products. However, the final products have relatively low economic value. For instance only $€ 2$ worth of compost is obtained per tonne food waste [16]. AD generates a slightly more valuable product: assuming the OFMSW typically contains $306.4 \mathrm{gCOD} \mathrm{kg}^{-1}$ of anaerobic biodegradable content [17] and that biogas conversion yields $€$ 0.25 worth of biogas per $\mathrm{kg}$ of COD [18], then a tonne of food waste will produce about $€ 76$ worth of biogas. However, the intermediate fermentation compounds produced during AD have a higher market value.

Fermentation to accumulate the intermediate carboxylates is known as the carboxylate platform. Producing carboxylates through fermentation forms a sustainable alternative to their current production from fossil fuels or extraction in small amounts from natural oils [19]. Compared to $\mathrm{AD}$, the carboxylate platform shows lower conversion yields, yet the higher product value and broader applications can result in a higher economic value [20]. In the last decade, particular interest has grown in medium chain carboxylic acids (MCCAs). They are defined as carboxylic acids with an aliphatic straight carbon chain of 6 to 12 carbon atoms, e.g., $n$-caproic acid has a straight chain of 6 carbon atoms (C6). MCCAs are more hydrophobic compared to shorter chain carboxylates, which makes them a more interesting fermentation product as it facilitates recovery from the fermentation broth [21]. In terms of potential value, C6 has a market size of 25,000 tonne per year, with an unrefined value of $\$ 1000$, and refined value of $\$ 2000$ to $\$ 3000$ per tonne [22,23]. Overall, MCCAs have a wide range of applications: they can be applied as growth-promoting antibiotic replacements in animal feed [24,25], or be converted via various bio-, thermo-, or electro-chemical processes into bulk fuels or solvents [14,26-28]. The production of MCCAs as higher value products from organic waste can incentivise for improved recycling while simultaneously replacing current unsustainable production processes.

MCCAs are produced by certain bacteria in a strongly reduced anaerobic environment, via a metabolic pathway that has been recently reviewed by Spirito et al. [29]. The bacteria gain energy by combining the oxidation of an electron donor, i.e., lactic acid or ethanol, to acetyl-CoA with the reductive elongation of acetyl-CoA with acetic acid (C2), propionic acid (C3), butyric acid (C4), pentanoic acid (C5), or caproic acid (C6) generating a carboxylic acid with 2 additional carbons at each step (Figure 1). The reduction step is required to provide sufficient Gibbs free energy $(\Delta \mathrm{G})$ to generate ATP in the initial oxidation step, restore the NAD ${ }^{+} / \mathrm{NADH}$ balance in the cell, and contribute to further energy generation via electron-transport phosphorylation. Ethanol and lactic acid have similar thermodynamic capacity to act as electron donors [30]. This chain elongation pathway is called the reverse $\beta$-oxidation pathway, since it is seen as the reversed biochemical degradation or $\beta$-oxidation of fatty acids.

Instead of using pure or engineered cultures, a consortium of microorganisms has more potential to deal with complex and variable feedstock such as organic waste. Mixed microbial cultures (MMC), also referred to as microbiomes, are communities of microorganisms within a well-defined environment of specific physicochemical properties [31]. Microbiomes are employed in biotechnology, for example in anaerobic digestion (AD), and in bioremediation by cultivating communities within contaminated 
soils $[32,33]$. The term "microbiome" is used to describe the mixed microbial communities related to the human and animal gut, mouth or skin, or plant rhizospheres.

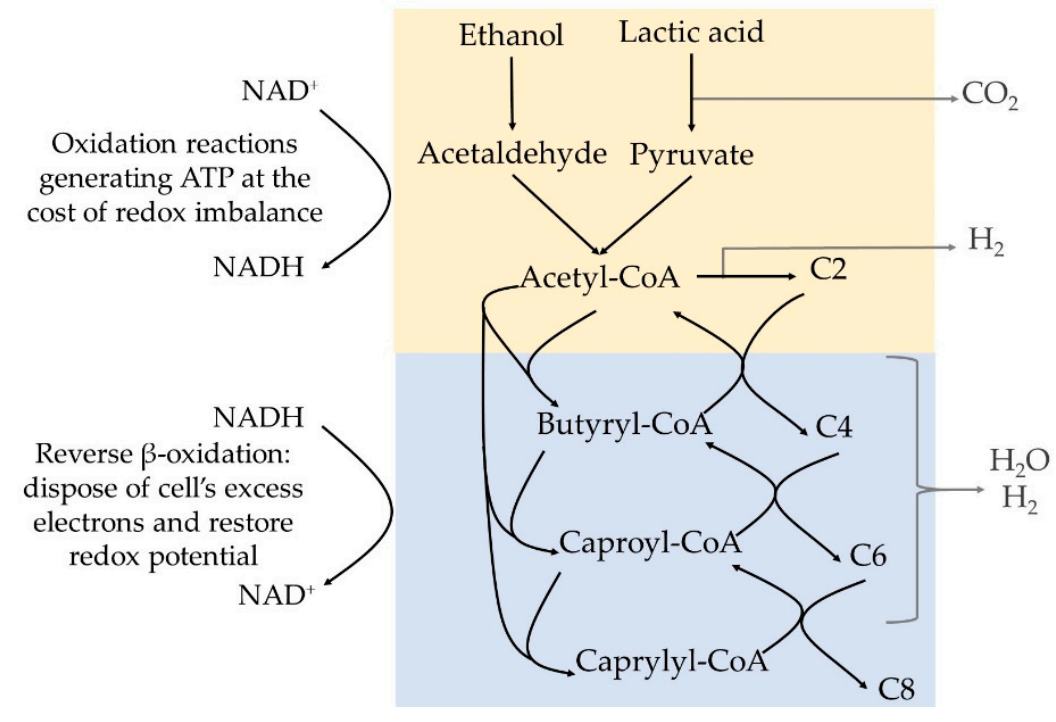

Figure 1. Simplified chain elongation pathways using ethanol or lactic acid as electron donors based on the metabolic pathways described in [29].

The first report of MMC that produced MCCAs dates back to the mid-19th Century, where Béchamp attributed the production of approx. $6 \mathrm{~g}_{\mathrm{COD}} \mathrm{L}^{-1} \mathrm{C} 6$ from ethanol, meat extract and chalk in a fermentation reactor to microbial activity [34]. A few decades later in the early 20th Century, an oily, immiscible layer comprising $5.3 \mathrm{gCOD} \mathrm{L}^{-1} \mathrm{C} 4$ and $6.4 \mathrm{~g}_{\mathrm{COD}} \mathrm{L}^{-1} \mathrm{C} 6$ was produced in a $30-$ day fermentation with impure cultures from a nutrient medium containing $24 \mathrm{gCOD}^{-1}$ ethanol [35]. Further microscopic study of the fermentation sludge revealed a consortia of microorganisms comprising methanogenic archaea and spore-forming bacteria [35]. By contrast with pure cultures, MMC do not require sterilisation, can degrade a complex feedstock, show a resilience to operational upsets [36], and allow continuous, long-term operation [37]. These advantages provide a strong argument for utilising microbiomes.

In $\mathrm{MMC}$, conversion of organic substrates occurs following a cascade of steps catalysed by different microorganisms that form synergistic and competitive interactions, resulting in a complex microbial ecosystem with a versatile metabolic capacity [38]. The different microbial groups can convert organic molecules into substrates available for chain elongating bacteria. In general, biodegradable organics are hydrolysed and fermented to intermediate compounds that acidify the medium, i.e., acidogenesis, including hydrogen gas $\left(\mathrm{H}_{2}\right)$, lactic acid, ethanol, formic acid $(\mathrm{C} 1)$ and volatile fatty acids (VFAs), i.e., straight short chain carboxylic acids with 2 to 4 carbon atoms. The accumulated intermediates can undergo several secondary bioconversion steps, including chain elongation to produce MCCAs (Figure 2) [26]. For instance, co-culture of the chain elongating bacteria Clostridium kluyveri with specific cellulolytic species or a rumen microbiome showed chain elongation potential from a cellulose substrate and ethanol $[39,40]$. The supporting community can even be designed or selected to allow chain elongation from a specific compound, such as glycerol or syngas (CO) [41-43], or allow the use of alternative electron donors such as, for instance, the cathode in a bio-electrochemical system $[44,45]$.

While it is generally believed that specific operational conditions allow development of a MMC for a functional and stable process [46], the broad metabolic capacity also gives rise to a set of various competitive reactions and by-products, especially when utilising a complex feedstock. Manipulating the environmental conditions, by regulating operation, allows some control to be exerted on the product spectrum, as it affects the thermodynamics of conversion processes, and therefore the microbiome 
composition that catalyses these conversions. However, current knowledge of control over the product outcome to improve MCCA yields in MMC fermentation is limited since experiments that use complex feedstock for MCCAs production have only emerged in the past few years.

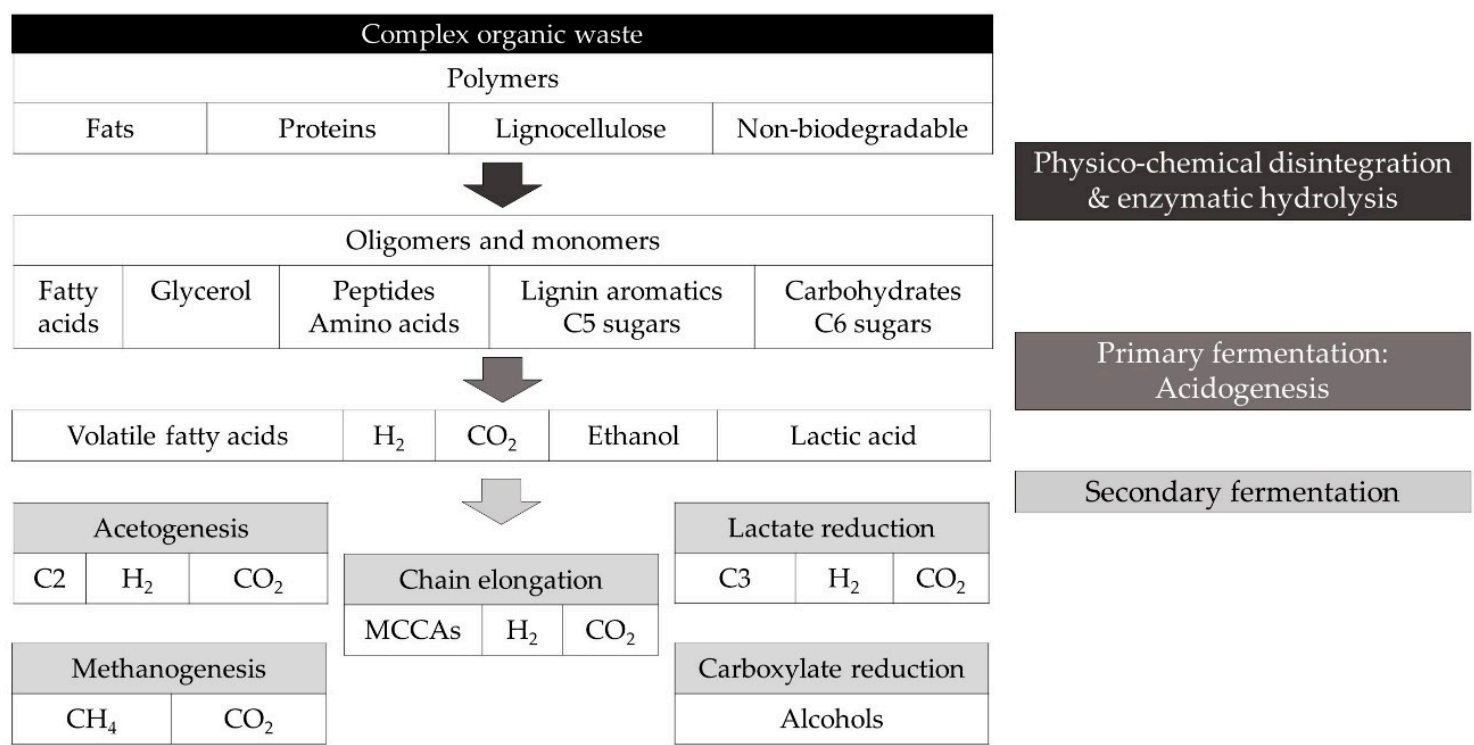

Figure 2. Simplified overview of fermentation pathways that can occur in MMC.

While the operational conditions that select for other MMC fermentation products such as volatile fatty acids (VFAs) [47] and hydrogen $\left(\mathrm{H}_{2}\right)$ [48] have been reviewed, the operational conditions or process set-up that allow MCC to be steered towards MCCA formation have to be further evaluated. A recent review is available regarding the use of bio-electrochemical systems for MCCA production as a complementary technology to AD [49]. Certain other reviews include a section on MCCAs as potential MMC fermentation products, either in the context of operational control applied in AD [50], or the contexts of a biorefinery [51], wastewater treatment [11] or food waste treatment [21,52-54]. However, a focussed analysis of the literature to identify and connect key operational parameters to target MCCA production from MMC fermentation of complex feedstocks is lacking. Therefore, this work aims to analyse the current literature, and hence complement existing reviews. For this, studies were included that specifically target chain elongation, but the scope was extended to include other MMC-based studies that have noted MCCA as by-products from, for instance, VFA or $\mathrm{H}_{2}$ production. Concentrations and production rates are converted to a COD-basis to allow comparison between studies using different reporting concentrations (Appendix A). The review evaluates the key operational parameters for MCCA production from complex substrates using MMC, with the objective of stimulating and accelerating research to produce sustainable, bio-based fuels and chemicals from organic waste. In addition, a database was generated from the experimental data available in the literature regarding MCCA production using MMC fermentation [55].

\section{Chain Elongation Behaviour of Pure Cultures Can Be Extended for MMC}

Chain elongation via ethanol is the most studied pathway to date. The mechanism has been elucidated by studying Clostridium kluyveri, a gram-positive, spore-forming bacteria from the phylum of Firmicutes whose whole genome has been published [56]. For each molecule of ethanol oxidized to $\mathrm{C} 2$, resulting in substrate-level ATP-generation and production of $\mathrm{H}_{2}$, five molecules of ethanol enter the reverse $\beta$-oxidation pathway as acetyl-CoA and elongate five molecules of $\mathrm{C} 2$ to $\mathrm{C} 4$. Subsequently, C4 can be elongated to C6 via ethanol-derived acetyl-CoA addition (Table 1, Equations (1) and (2)) [29]. In reality, the pathway of C. kluyveri has a more flexible stoichiometry influenced by substrate concentrations, ratio of ethanol to acetate, and the partial pressure of $\mathrm{H}_{2}$ (Table 1 , 
Equations (3)-(6)) [57-59]. It also has a broader substrate range including propanol as an electron donor, or propionate (C3), succinate, malonate, 3-butenoate, 4-hydroxybutyrate and crotonate as electron acceptors $[39,60,61]$. Pure culture fermentations of $C$. kluyveri fed with ethanol and C2 mixtures have been reported to produce $\mathrm{C} 6$ up to $10.2 \mathrm{~g}_{\mathrm{COD}} \mathrm{L}^{-1} \mathrm{~d}^{-1}$ in continuous culture [62] and to reach concentrations up to $30.7 \mathrm{~g}_{\mathrm{COD}} \mathrm{L}^{-1}$ after $72 \mathrm{~h}$ of batch culture [60].

Chain elongation via lactic acid has been reported for other bacteria in the phylum of Firmicutes, such as Megasphaera elsdenii [63] and a Ruminococcaceae bacterium CPB6 [64]. Other wild-type bacteria are known to perform chain elongation and produce C6 (and C8) using more "exotic" chain elongating substrates such as simple sugars, polyols, methanol, amino acids and $\mathrm{H}_{2}$ and $\mathrm{CO}_{2}$ gas mixtures as reviewed by Angenent et al. [58]. In addition, pathways have been engineered to produce C6. For instance, to improve yields the genes from Megasphaera sp. were expressed in Escherichia coli, and approx. $1.17 \mathrm{~g}_{\mathrm{COD}} \mathrm{L}^{-1} \mathrm{~d}^{-1} \mathrm{C} 6$ was obtained after $36 \mathrm{~h}$ of batch fermentation [65]. To develop a more thermo-tolerant and acid-resistant biocatalyst, biosynthetic pathways have been constructed in the yeast Kluyveromyces marxianus [66]. Single-strains or engineered cultures have their place when the product is of high enough value and require a certain purity. Overall, the production of MCCAs, and other medium chain chemicals, using pure, engineered cultures has been recently reviewed by other authors, e.g., Sarria et al. [67] and Su et al. [68].

Table 1. Chain elongation reactions via ethanol and lactic acid and thermodynamic information with concentrations and pressures of all components at $1 \mathrm{M}$ or 1 bar, $\mathrm{pH} 7$ at $25^{\circ} \mathrm{C}$.

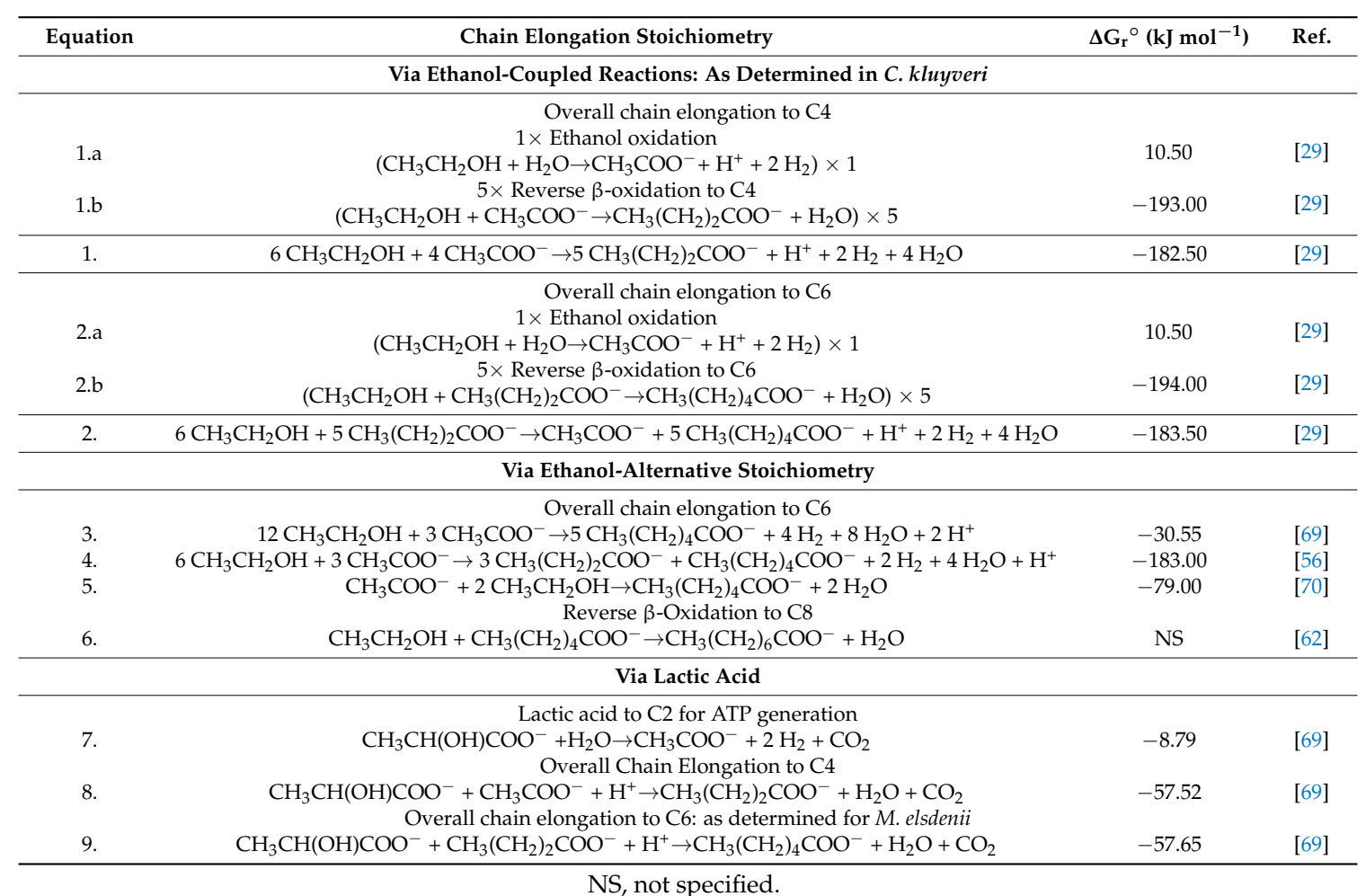

However, when it comes to breaking down a complex feedstock such as organic waste, the focus of this review, pure cultures have limited metabolic capacity, reducing their potential for an effective treatment and requiring more expensive processing such as media sterilisation [71]. This can be circumvented by using MMC instead of pure cultures. Chain elongation in MMC happens in a similar manner than with pure cultures. For instance, microbiomes grown in ethanol-rich conditions show similar characteristics to pure culture fermentation, such as higher specificity towards longer chain carboxylates at higher ethanol/acetate ratios $[72,73]$ and elongation towards a mixture of even- and uneven MCCA in the presence of propanol or C3 [74,75]. It should be noted that MMC are unable to use either 4-carbon alcohols or 5-carbon carboxylates as initial substrate sources for chain elongation 
at similar concentrations than for example ethanol or acetate [75]. This may be due to longer chain substrates having higher toxicity and possible inhibition of the microbiome. In addition, microbiomes are capable of adapting to substrate fluctuations: MMC obtained from ethanol-based chain elongation reactors acclimatised to produce $\mathrm{C} 6$ when fed with methanol or lactic acid as an alternate electron donor $[76,77]$.

\section{Thermodynamic Models and MMC Composition Determine Competitive Processes}

Successful production of MCCAs requires elimination of competing reactions that could consume the substrate or product. Some example reactions include methanogenesis, sulphate reduction, lactate reduction to propionate (C3), excessive oxidation of ethanol, and reduction or oxidation of carboxylic acids, as described in Table 2. Since anaerobic ecosystems are energy-limited with $\Delta G$ of conversion processes being close to $0 \mathrm{~kJ} \mathrm{~mol}^{-1}$ (Tables 1 and 2) [78], the thermodynamic favourability of bioconversion processes can shift by small changes in substrate or product concentrations, $\mathrm{pH}$ and temperature, partial pressure of gases in reactor headspace, or substrate availability $[50,79,80]$. The resulting thermodynamic constraints select for the viable bioconversion reactions and, hence, the composition of microbiome that has the most efficient catabolic system [81,82]. Therefore, strategies to inhibit competitive reactions can be classified as; (i) the inhibition of a specific, competitive trophic group, or (ii) the engineering of the fermentation environment to reduce the potential competitive reactions. For instance, methanogenesis, the ability to produce $\mathrm{CH}_{4}$, is limited to certain archaea. Since $\mathrm{CH}_{4}$ has the lowest free energy content per electron upon oxidation to $\mathrm{CO}_{2}$ under anaerobic conditions, and automatically leaves the reactor as a gas, it will be produced by methanogens in $\mathrm{MMC}$ to optimally use the energy available [71]. To ensure that $\mathrm{C} 2$ or $\mathrm{H}_{2}$ are not lost to $\mathrm{CH}_{4}$ and $\mathrm{CO}_{2}(\mathrm{Table} 2$, Equations (10) and (11)), specific methanogenic inhibitors can be added to promote chain elongation. For instance, in batch fermentation of a synthetic substrate containing ethanol and $\mathrm{C} 2$, the addition of 2-bromoethylsulfonate (BES) tripled C6 production to $19 \mathrm{gCOD}^{-1}$ [83]. Alternatively, to avoid the cost of such chemicals, specific operational conditions such as $\mathrm{pH}$ or hydraulic retention time (HRT) can be selected to inhibit methanogens as discussed subsequently. Another unwanted trophic group are the sulphate reducing bacteria. A sulphur-rich feedstock will result in sulphate reduction, as this is more thermodynamically favourable than C6 production (Table 2, Equation (12)), generating sulphide, which is both toxic for most bacteria and corrosive to fermentation equipment [84].

Thermodynamic models are useful tools to improve understanding of the chain elongation pathway in MMC and to determine which operational parameters allow to regulate the product spectrum. Research has developed kinetic and thermodynamic models based on pure culture chain elongation using C. kluyveri $[69,85]$ or metabolic energy-based models to predict MMC fermentation of simple substrates such as glucose [86]. Such models can help understanding the occurrence of chain elongation at different ethanol concentrations [58], or at varying $\mathrm{H}_{2}: \mathrm{CO}_{2}$ ratios [30]. There is a lack of models that evaluate the thermodynamics of the lactic acid-based chain elongation route. At standard conditions lactate reduction (Table 2, Equations (13) and (14)) releases more energy than chain elongation via lactic acid (Table 1, Equation (9)). Experimentally, Kucek et al. [77] found increasing lactate loading rate with a synthetic feedstock initially improved chain elongation in MMC fermentation, yet increasing influent lactic acid from 9.1 to $16.2 \mathrm{gCOD} \mathrm{L}^{-1} \mathrm{~d}^{-1}$ led to a collapse of $\mathrm{C} 6$ productivity to $3.0 \mathrm{gCOD}^{-1} \mathrm{~d}^{-1}$ while $\mathrm{C} 3$ production increased to $5.5 \mathrm{gCOD}_{\mathrm{C}}^{-1} \mathrm{~d}^{-1}$. This was attributed to the competitive acrylate pathway being stimulated ahead of chain elongation at elevated lactic acid concentrations [77,87]. In contrast, another study operating with an excess of lactic acid did not report C3 production; the addition of three spikes in a fed batch-style adding a total about $26.7 \mathrm{gCOD} \mathrm{L}^{-1}$ lactic acid to the synthetic medium resulted in $\mathrm{C} 6$ accumulation of up to 51.7 gCOD $^{-1}$ [88]. The development of thermodynamic models focusing on lactic acid-based chain elongation might shed more light on these competitive pathways.

Modelling thermodynamics only goes so far, and the composition of the microbiome must be considered as this can influence the microbiome's metabolic capacity. The results from microbial 
community composition analysis using 16s rRNA gene sequencing of the mentioned studies cited above indicate they had a different microbiome structure. The fermentation where the acrylate pathway took over, had a wider variety of prokaryotic families and was dominated by Acinetobacter spp. (approx. $60 \%$ relative abundance) and the operational taxonomic units belonging to Ruminococcaceae were less than $10 \%$ [77]. On the contrary, the study with minimal C3 production was dominated by a Clostridium cluster IV group (79.1\%, belonging to Ruminococcaceae) [88].

Studying the microbiome composition improves the understanding of the MMC fermentation mechanisms. For instance, when following the microbial community dynamics of maize silage fermentation in a leach bed reactor (LBR), Sträuber et al. [89] found Lactobacillus and Acetobacter strains dominated during the first days of operation, with lactic and acetic acid as concurrent products. However, Clostridium species became dominant on Days 3 and 4 resulting in a $\mathrm{pH}$ increase and $\mathrm{C} 4$ and C6 production, and in turn these were overgrown during Days 5 to 7 by other phylotypes capable of using more complex polysaccharides by different metabolism [89]. Further investigation of microbial interactions and synergies will allow better design of MCCA production processes from complex feedstocks, for example operating in sequential batch mode to allow the different trophic groups to first accumulate ethanol, lactic acid, $\mathrm{H}_{2}$ or VFAs for subsequent chain elongation. Only 20 studies on MCCA production could be found, so far, that include an analysis of the microbial community. This usually involves DNA extraction and sequencing of $16 \mathrm{~s}$ rRNA amplicon and comparison to sequence databases [23,70,73,75,77,83,88,90-99], sometimes in addition to other community analysis such as flow cytometry [100], analysis of terminal restriction fragment length polymorphisms (T-RFLP) [101] or microscopic evaluation [102].

Table 2. Biochemical reactions that compete with chain elongation and their thermodynamic information with concentrations and pressures of all components at $1 \mathrm{M}$ or 1 bar.

\begin{tabular}{|c|c|c|c|}
\hline Equation & Competitive Reactions for Chain Elongation & $\Delta \mathrm{G}_{\mathrm{r}}^{\circ}$ or $\Delta \mathrm{G}_{\mathrm{r}}{ }^{\prime \prime}\left(\mathrm{kJ} \mathrm{mol}^{-1}\right)$ & Ref. \\
\hline 10. & $\begin{array}{l}\text { Hydrogenotrophic methanogenesis } \\
\qquad 4 \mathrm{H}_{2}+\mathrm{CO}_{2} \rightarrow \mathrm{CH}_{4}+2 \mathrm{H}_{2} \mathrm{O}\end{array}$ & $-125.84^{a}$ & [26] \\
\hline 11. & $\begin{array}{l}\text { Acetoclastic methanogenesis } \\
\mathrm{CH}_{3} \mathrm{COO}^{-}+\mathrm{H}^{+} \rightarrow \mathrm{CH}_{4}+\mathrm{CO}_{2}\end{array}$ & $-39.06^{\mathrm{a}}$ & [26] \\
\hline 12. & $\begin{array}{c}\text { Sulphate reduction } \\
\mathrm{CH}_{3} \mathrm{COO}^{-}+3 \mathrm{H}^{+}+\mathrm{SO}_{4}^{-2} \rightarrow \mathrm{H}_{2} \mathrm{~S}+2 \mathrm{H}_{2} \mathrm{O}+2 \mathrm{CO}_{2} \\
2 \mathrm{CH}_{3} \mathrm{CH}(\mathrm{OH}) \mathrm{COO}^{-}+\mathrm{SO}_{4}^{-2} \rightarrow \mathrm{H}_{2} \mathrm{~S}+2 \mathrm{CH}_{3} \mathrm{COO}^{-}+2 \mathrm{HCO}_{3}^{-} \\
2 \mathrm{CH}_{3} \mathrm{CH}_{2} \mathrm{OH}+\mathrm{SO}_{4}^{-2} \rightarrow \mathrm{H}_{2} \mathrm{~S}+2 \mathrm{CH}_{3} \mathrm{COO}^{-}+2 \mathrm{H}_{2} \mathrm{O} \\
4 \mathrm{H}_{2}+2 \mathrm{H}^{+}+\mathrm{SO}_{4}^{-2} \rightarrow \mathrm{H}_{2} \mathrm{~S}+4 \mathrm{H}_{2} \mathrm{O}\end{array}$ & $\begin{array}{l}-64.39^{b} \\
-82.92^{b} \\
-69.29^{b} \\
-39.70^{b}\end{array}$ & [69] \\
\hline 13. & $\begin{array}{l}\text { Lactate reduction to C3: as found in Selenomonas ruminantium } \\
\mathrm{CH}_{3} \mathrm{CH}(\mathrm{OH}) \mathrm{COO}^{-}+\mathrm{H}_{2} \mathrm{O} \rightarrow \mathrm{CH}_{3} \mathrm{COO}^{-}+\mathrm{CO}_{2}+2 \mathrm{H}_{2} \times 1 \\
\mathrm{CH}_{3} \mathrm{CH}(\mathrm{OH}) \mathrm{COO}^{-}+\mathrm{H}_{2} \rightarrow \mathrm{CH}_{3} \mathrm{CH}_{2} \mathrm{COO}^{-}+\mathrm{H}_{2} \mathrm{O} \times 2\end{array}$ & $\begin{array}{l}28.51^{\mathrm{a}} \\
-86.63^{\mathrm{a}}\end{array}$ & [26] \\
\hline 14. & $\begin{array}{l}\text { Lactate reduction to C3: as determined for C. propionicum } \\
\qquad \mathrm{CH}_{3} \mathrm{CH}(\mathrm{OH}) \mathrm{COO}^{-}+\mathrm{H}_{2} \rightarrow \mathrm{CH}_{3} \mathrm{CH}_{2} \mathrm{COO}^{-}+\mathrm{H}_{2} \mathrm{O}\end{array}$ & $-83.80^{b}$ & [47] \\
\hline 15. & $\begin{array}{c}\text { Carboxylate to alcohol reduction with } \mathrm{H}_{2} \\
\mathrm{CH}_{3} \mathrm{COO}^{-}+\mathrm{H}^{+}+2 \mathrm{H}_{2} \rightarrow \mathrm{CH}_{3} \mathrm{CH}_{2} \mathrm{OH}+\mathrm{H}_{2} \mathrm{O} \\
\mathrm{CH}_{3} \mathrm{CH}_{2} \mathrm{COO}^{-}+\mathrm{H}^{+}+2 \mathrm{H}_{2} \rightarrow \mathrm{CH}_{3}\left(\mathrm{CH}_{2}\right)_{2} \mathrm{OH}+\mathrm{H}_{2} \mathrm{O} \\
\mathrm{CH}_{3}\left(\mathrm{CH}_{2}\right)_{2} \mathrm{COO}^{-}+\mathrm{H}^{+}+2 \mathrm{H}_{2} \rightarrow \mathrm{CH}_{3}\left(\mathrm{CH}_{2}\right)_{3} \mathrm{OH}+\mathrm{H}_{2} \mathrm{O} \\
\mathrm{CH}_{3}\left(\mathrm{CH}_{2}\right)_{4} \mathrm{COO}^{-}+\mathrm{H}^{+}+2 \mathrm{H}_{2} \rightarrow \mathrm{CH}_{3}\left(\mathrm{CH}_{2}\right)_{5} \mathrm{OH}+\mathrm{H}_{2} \mathrm{O}\end{array}$ & $\begin{array}{l}-7.22^{\mathrm{a}} \\
-7.49^{\mathrm{a}} \\
-3.58^{\mathrm{a}} \\
-7.55^{\mathrm{a}}\end{array}$ & [12] \\
\hline 16. & $\begin{array}{l}\text { Ethanol oxidation: as determined for } \mathrm{C} \text {. formicoaceticum } \\
\qquad 2 \mathrm{CH}_{3} \mathrm{CH}_{2} \mathrm{OH}+2 \mathrm{CO}_{2} \rightarrow 3 \mathrm{CH}_{3} \mathrm{COO}^{-}+3 \mathrm{H}^{+}\end{array}$ & $-76.90^{b}$ & [47] \\
\hline 17. & $\begin{array}{l}\text { Coupled ethanol oxidation and } \mathrm{C} 3 \text { reduction } \\
\mathrm{CH}_{3} \mathrm{CH}_{2} \mathrm{OH}+\mathrm{H}_{2} \mathrm{O} \rightarrow \mathrm{CH}_{3} \mathrm{CHOO}^{-}+\mathrm{H}^{+}+2 \mathrm{H}_{2} \times 1 \\
\mathrm{CH}_{3} \mathrm{CH}_{2} \mathrm{COO}^{-}+\mathrm{H}^{+}+2 \mathrm{H}_{2} \rightarrow \mathrm{CH}_{3}\left(\mathrm{CH}_{2}\right)_{2} \mathrm{OH}+\mathrm{H}_{2} \mathrm{O}\end{array}$ & $\begin{array}{l}7.22^{\mathrm{a}} \\
-7.49^{\mathrm{a}} \\
\end{array}$ & [26] \\
\hline
\end{tabular}

Recently, Scarborough et al. [103] combined metagenomic, metatranscriptomic and thermodynamic analysis of samples from a reactor microbiome fermenting a lignocellulosic-based feedstock in continuous stirred-tank reactor (CSTR) mode, which allowed, for instance, affiliation of Lactobacillus and members of the Coriobacteriaceae family to hydrolysis and primary fermentation, and organisms related to Lachnospiraceae and Eubacteriaceae to MCCA production. In addition, the recent 
advancements in metagenomic and metatranscriptomic analysis led to the proposition that other MCCA-producing pathways occur in a microbiome, such as the fatty acid biosynthesis pathway, alongside the reverse $\beta$-oxidation pathway [104].

Research is necessary to expand the thermodynamic models to include both the MMC composition, which indicates the potential bio-reactions in a system, and the composition of complex feedstocks. The development of these models will complement the understanding obtained from experimental studies, and will help in determining the operational parameters which select for MCCA production over competitive reactions. In addition, culture-independent analysis and increased application of "omics" approaches on MMC fermentation studies will be essential to enhance our understanding of the underlying mechanisms that include competitive and synergistic processes and the importance of the MMC composition.

\section{Bio-Waste Composition and Its Effect on Chain Elongation}

A feedstock suitable for chain elongation should provide the necessary substrates, i.e., VFAs and electron donors such as ethanol or lactic acid. Chain elongation substrates can either be directly present in the feedstock, indirectly produced from primary fermentation in vivo, or supplemented. The highest MCCA production rates obtained in MMC fermentation used a synthetic feedstock, hence a readily bio-available substrate. In up-flow reactors (URs) with biomass retention, $115.2 \mathrm{~g}_{\mathrm{COD}} \mathrm{L}^{-1} \mathrm{~d}^{-1}$ for C6 [105] and $19.4 \mathrm{~g}_{\mathrm{COD}} \mathrm{L}^{-1} \mathrm{~d}^{-1}$ for $\mathrm{C} 8$ [96] were obtained from ethanol and $\mathrm{C} 2$ mixtures. These rates are more than 10 times higher than that achieved so far using complex, un-supplemented feedstocks (Table 3). If electron donors, such as ethanol or lactic acid, are supplemented, selectivity of secondary fermentation is enhanced towards chain elongation. Ethanol-supplemented organic waste streams have reached production rates that lie somewhat in between synthetic and complex feedstocks. The maximum reported is $60.7 \mathrm{~g}_{\mathrm{COD}} \mathrm{L}^{-1} \mathrm{~d}^{-1} \mathrm{C} 6$ and $2.13 \mathrm{~g}_{\mathrm{COD}} \mathrm{L}^{-1} \mathrm{~d}^{-1} \mathrm{C} 8$ for pre-fermented OFMSW supplemented with $97.4 \mathrm{~g}_{\mathrm{COD}} \mathrm{L}^{-1} \mathrm{~d}^{-1}$ ethanol [106]. Supplementation of $21.3 \mathrm{~g}_{\mathrm{COD}} \mathrm{L}^{-1}$ lactic acid to pre-treated grass in batch fermentation with an adapted inoculum resulted in a total $\mathrm{C} 6$ concentration of $24.1 \mathrm{~g}_{\mathrm{COD}} \mathrm{L}^{-1}$ after 1 day [95].

When applying a supplementation strategy, certain experiments show that excessive concentrations of ethanol and lactic acid should be avoided. An upper limit for ethanol-based chain elongation is reported at $97.4 \mathrm{gCOD}_{\mathrm{CO}} \mathrm{L}^{-1}$ after which it exerts an inhibitory effect [107]. Grootscholten et al. [108] spiked a LBR processing OFMSW at four intervals with $11.2 \mathrm{gCOD} \mathrm{L}^{-1}$ ethanol during batch fermentation. This increased MCCA concentration from 4.0 to $6.0 \mathrm{~g}_{\mathrm{COD} \mathrm{L}} \mathrm{L}^{-1}$ for $\mathrm{C} 6$ and 0.0 to $1.2 \mathrm{gCOD} \mathrm{L}^{-1}$ for C8 compared to a non-supplemented control experiment, yet the total amount of carboxylic acids produced was lower [108]. This was attributed to ethanol inhibition of hydrolytic and acidogenic bacteria [108]. To avoid ethanol inhibition limiting primary fermentation, Grootscholten et al. [106] suggested the use of a two-stage system where hydrolysis and primary fermentation of OFMSW occurs in the first batch phase, and in the second the pre-fermented OFMSW is supplemented with ethanol to select for chain elongation in a CSTR. The disadvantages of two-stage systems are the increased operational complexity and additional capital and operational costs.

A life-cycle assessment on C6 production from ethanol-supplemented food waste fermentation in a lab- and pilot-scale system revealed that the largest environmental effects (acidification and eutrophication potential) result from addition of caustic soda to control $\mathrm{pH}$ and ethanol as electron donor [109]. Thus, supplementation of electron donors to stimulate chain elongation should be minimized or avoided. Instead of supplementing the feedstock, several studies have split the overall fermentation into two stages. Firstly, specific operational conditions are selected to accumulate ethanol or lactic acid. Then in a second phase, the leftover organics in the effluent are fermented towards VFAs and elongated with the electron donor under chain elongating conditions. Ethanol-rich substrates fed into chain elongation reactors have been obtained from yeast-based fermentations, such as for the production of bio-ethanol which generates an ethanol-rich beer and a residue after distillation called stillage [27,37,93], or residues from the production of wine [97], or effluent from 
syngas fermentation [110]. Lactate-rich substrates can be obtained via MMC fermentations selective for lactic acid, such as effluent from thermophilic acid whey fermentation [94], and pre-fermented grass (i.e., grass silage) [95] or maize silage [27,89]. Whey is rich in lactose, simple sugars such as fructose that are easily fermented to produce lactic acid [111]. Food waste contains lactic acid bacteria that are easily enriched in MMC fermentation, to produce lactic acid up to concentrations of 21.3 to 48 gCOD L $^{-1}$ [112-114]. Maximum production using ethanol- and lactic acid-rich streams in MMC fermentation without additional supplementation have been reached using diluted beer (7.52 gCOD $\mathrm{L}^{-1} \mathrm{~d}^{-1} \mathrm{C} 6$ ) [46] and acidified whey from the quark industry $\left(5.12 \mathrm{gCOD}^{-1} \mathrm{~d}^{-1} \mathrm{C6}\right)$ [85]. The disadvantages of two-stage systems for accumulation of electron donors are the increased operational complexity and additional capital and operational costs.

An alternative to supplemented or pre-fermented organic feedstock, would be to operate a single-phase process where the substrate itself is converted to lactic acid and/or ethanol in parallel with the chain elongation reactions. Recently, C6 has been produced in a one-stage LBR from food waste up to concentrations of $21.8 \mathrm{gCOD}^{-1}$ and a rate of $3.12 \mathrm{gCOD} \mathrm{L}^{-1} \mathrm{~d}^{-1}$ [91], comparable to a supplemented and/or two-stage system. In this study, batch tests inoculated with the LBR leachate showed that lactic acid was consumed in favour of ethanol as the electron donor [91]. Other studies aimed at VFA or $\mathrm{H}_{2}$ production have produced $\mathrm{C} 6$ in a single-stage approach from food waste, without supplementation, and at similar production rates. In studies aimed at $\mathrm{H}_{2}$ production using glucose-rich synthetic wastewater [115] or simulated food waste [116] as feedstock, C6 was produced at rates higher than experiments which targeted MCCA production (Table 3). Therefore, food waste and similar complex substrates might be a promising feedstock.

The use of complex feedstock comes with a set of challenges. Firstly, the composition of the feedstock will influence certain competitive processes and the intermediates that result from hydrolysis and acidogenesis, and therefore affects the potential for chain elongation. For example, VFA yields in MMC fermentation have shown to be less for lipid-rich waste compared to carbohydrate- or protein-rich wastes, due to difficulties in hydrolysis [117]. In addition, the type of carbohydrates [118] or proteins [119] in the substrate also influences the metabolic pathways. Secondly, it is important to recognise that seasonal and geographical variation in organic waste streams impacts composition and availability of feedstock. This can often become a challenge when designing a suitable treatment or valorisation (bio-)process that is robust and flexible, especially when relying on pure microbial cultures. For instance, OFMSW may contain small quantities of bio-waste from various origins, such as discarded oils, fruits, animal-derived products and more lignocellulose-rich leaves and stems from vegetables, resulting in an overall feedstock comprising both easily biodegradable carbohydrates and proteins as more recalcitrant matter [120]. It was found that a LBR fed with OFMSW which was richer in green waste had lower production of carboxylic acids compared to OFMSW containing more food waste [121]. Lastly, not every type of substrate will allow chain elongation to occur. In batch experiments aimed at VFA production, seven types of "food waste" feedstocks were tested and only four produced C6. These were cheese whey, sugarcane molasses, the organic fraction of municipal solid waste, and winery effluent [122]. Similarly, in sequential batch reactors (SBRs), the fermentation of cheese whey resulted in $0.12 \mathrm{gCOD}^{-1} \mathrm{~d}^{-1} \mathrm{C} 6$, while in similar operating conditions the fermentation of sewage sludge produced more total carboxylic acids but very little C6 [123]. Therefore, the right type of complex feedstock should be selected for MCCA production to be successful—this is not well understood and requires further investigation. 
Table 3. Overview of feedstock, operating parameters and product outcome (as C6 production and C7 or C8 when data available) in continuous MMC fermentation.

\begin{tabular}{|c|c|c|c|c|c|c|c|c|c|}
\hline \multirow{2}{*}{ Feedstock } & \multirow{2}{*}{ Reactor (a) } & \multirow{2}{*}{$\begin{array}{c}\mathrm{pH} \\
-\end{array}$} & \multirow{2}{*}{$\begin{array}{c}\mathrm{T} \\
{ }^{\circ} \mathrm{C} \\
\end{array}$} & \multirow{2}{*}{$\begin{array}{c}\text { OLR } \\
\mathrm{g}_{\mathrm{COD}} \mathrm{L}^{-1} \mathrm{~d}^{-1} \\
\end{array}$} & \multirow{2}{*}{$\begin{array}{c}\text { HRT } \\
\text { d }\end{array}$} & \multicolumn{2}{|c|}{$\mathrm{C} 6(\mathrm{C} 7, \mathrm{C} 8)$} & \multirow{2}{*}{$\begin{array}{c}\text { Target } \\
\text { Product }\end{array}$} & \multirow{2}{*}{ Ref. } \\
\hline & & & & & & $g_{\text {COD }} L^{-1} d^{-1}$ & $\mathrm{~g}_{\mathrm{COD}} \mathrm{L}^{-1}$ & & \\
\hline \multicolumn{10}{|c|}{ Ethanol Rich } \\
\hline Diluted yeast fermentation beer & SBR $(48 \mathrm{~h})^{\mathrm{b}}$ & 5.5 & 30 & 10.70 & 15 & 7.52 & NA & MCCAs & [37] \\
\hline Diluted yeast fermentation beer & SBR $(48 \mathrm{~h})$ & 5.5 & 30 & 5.70 & 12 & 4.62 & NA & MCCAs & [93] \\
\hline Diluted wine fermentation residue & $\mathrm{UR}^{\mathrm{b}}$ & 5.2 & 37 & 51.90 & 0.9 & $4.1(0.3,2.5)$ & NA & MCCAs & [97] \\
\hline Yeast fermentation beer and thin stillage & SBR $(24 \mathrm{~h})$ & 5.5 & 35 & 2.89 & 7 & 2.55 & 17.90 & MCCAs & [92] \\
\hline Yeast fermentation beer & SBR $(48 \mathrm{~h})$ & 6.5 & 30 & 7.64 & 15 & 1.74 & NA & MCCAs & [27] \\
\hline Syngas fermentation effluent, with nutrients & $\mathrm{UR}^{\mathrm{b}}$ & 5.5 & 30 & 51.80 & 0.58 & 3.80 & 2.25 & MCCAs & [110] \\
\hline \multicolumn{10}{|c|}{ Lactic Acid Rich } \\
\hline Acid whey from quark industry & $\mathrm{UR}^{\mathrm{b}}$ & 5.5 & 30 & 28.80 & 2.5 & 5.12 & NA & MCCAs & {$[100]$} \\
\hline Pre-fermented acid whey yoghurt industry & $\mathrm{UR}^{\mathrm{b}, \mathrm{ex}}$ & 5.0 & 30 & 10.90 & 2.1 & 3.08 & $<1.00$ & MCCAs & [94] \\
\hline Diluted yellow water & USBR $(67.2 \mathrm{~h})$ & 6.0 & 30 & 8.67 & 28 & 1.85 & 51.70 & MCCAs & [88] \\
\hline Diluted cheese whey powder & $\mathrm{UR}^{\mathrm{b}}$ & 6.0 & 37 & 5.36 & 4 & 0.70 & 2.80 & VFAs & [111] \\
\hline Cheese whey & SBR $(24 \mathrm{~h})$ & NA & 35 & 6.00 & 12 & $0.12 *$ & $1.45^{*}$ & VFAs & [123] \\
\hline \multicolumn{10}{|c|}{ (Ligno) Cellulosic Based } \\
\hline Switchgrass-derived stillage & CSTR & 5.5 & 35 & 7.20 & 2 & $5.74(\mathrm{NA}, 0.66)$ & $18.70(\mathrm{NA}, 2.40)$ & MCCAs & [99] \\
\hline Pre-fermented grass & SBR $(24 \mathrm{~h})$ & NA & 32 & 5.30 & 2 & 4.52 & 9.03 & MCCAs & [95] \\
\hline Corn-derived thin stillage & $\operatorname{SBR}(48 \mathrm{~h})^{\mathrm{ex}}$ & $5.4-5.7$ & 35 & 18.00 & 3 & $1.14(0.10,0.00)$ & NA & MCCAs & [23] \\
\hline Pre-treated corn fibre: dilute-acid/dilute-alkali/hot water & SBR $(48 \mathrm{~h})$ & 5.5 & 55 & 1.92 & 15 & $0.6 * / 0.39 * / 0.12 *$ & NA & VFAs & [36] \\
\hline Paper fines and industrial bio-sludge (40:60) & $\mathrm{SBR}^{\mathrm{a}}$ & NA & 40 & $2.6 \mathrm{gVS} \mathrm{L}^{-1}$ & 16 & $0.42(0.08, \mathrm{NA})$ & $6.67(1.36, \mathrm{NA})$ & MCCAs & [124] \\
\hline \multicolumn{10}{|c|}{ Food Waste } \\
\hline Simulated food waste & SBR (24 h) & $5-6$ & 34 & $30 \mathrm{~g}_{\mathrm{TS}} \mathrm{L}^{-1}$ & 3 & $8.09 *$ & $24.30 *$ & $\mathrm{H}_{2}$ & [116] \\
\hline Restaurant food waste & LBR (7 days) & NA & 37 & 16.60 & 7 & 3.12 & 21.80 & MCCAs & [91] \\
\hline Cafeteria food waste & SBR $(24 \mathrm{~h})$ & 5.5 & 45 & $9 \mathrm{~g}_{\mathrm{TS}} \mathrm{L}^{-1} \mathrm{~d}^{-1}$ & 8 & 1.28 & 10.30 & VFAs & [125] \\
\hline Vegetable and salad waste & SBR $(24 \mathrm{~h})$ & $5-7.5$ & 35 & 0.57 & 20 & 0.25 * & $5.08^{*}$ & VFAs & [126] \\
\hline \multicolumn{10}{|c|}{ Other } \\
\hline Sucrose-rich synthetic wastewater & UR & 3.6 & 35 & 15.80 & 0.71 & 5.70 & 4.03 & $\mathrm{H}_{2}$ & [115] \\
\hline Synthetic glucose medium & $\mathrm{UR}^{\mathrm{b}}$ & NA & 30 & 204.00 & 0.10 & $4.13 *$ & $0.43 *$ & $\mathrm{H}_{2}$ & [127] \\
\hline Primary and waste activated sludge & SBR $(24 \mathrm{~h})$ & NA & 35 & 79.90 & 1 & $<0.08^{*}$ & $<0.08^{*}$ & VFAs & [123] \\
\hline \multicolumn{10}{|c|}{ Food Waste with Ethanol Supplementation } \\
\hline Pre-fermented OFMSW, $44.8 \mathrm{~g}_{\mathrm{COD}} \mathrm{L}^{-1}$ ethanol, $\mathrm{CO}_{2}$ & $\mathrm{UR}^{\mathrm{b}}$ & 6.75 & 30 & NA & 0.46 & $60.70(4.59,2.13)$ & $27.80(2.10,0.98)$ & MCCAs & [106] \\
\hline Pre-fermented food waste, $78.4 \mathrm{gCOD} \mathrm{L}^{-1}$ ethanol, $\mathrm{CO}_{2}$ & $\operatorname{CSTR}^{\mathrm{b}}$ & 6.8 & 30 & 28.90 & 4 & 12.80 & 51.20 & MCCAs & [128] \\
\hline Pre-fermented food waste, $78.4 \mathrm{~g}_{\mathrm{COD}} \mathrm{L}^{-1}$ ethanol, $\mathrm{CO}_{2}$ & CSTR $^{b}$ & 6.8 & 30 & 115.00 & 1 & $12.40(0.33,0.42)$ & $15.70(0.18,0.18)$ & MCCAs & [128] \\
\hline
\end{tabular}

SBR: sequential batch reactor; UR: up-flow reactor; CSTR: continuous stirred tank reactor; NA: not applicable; ${ }^{\text {a }}$ fermentation cycle in case of SBR or semi-batch; ${ }^{\text {b }}$ biomass retention; ${ }^{\text {ex }}$ in situ extraction; * estimated from graphs. When values were not directly reported by cited study these were estimated as described in Appendix A. 


\section{Environmental Conditions that Influence Chain Elongation}

\subsection{Mesophilic Temperatures Seem to Benefit Chain Elongation}

Temperature has a significant influence on energy released from reactions [80], alters the microbial community composition [129], and affects the kinetic rates of metabolic reactions. The amount of research focusing on the effect of temperature on chain elongation is limited, yet results so far indicate operation in the mesophilic range, typically between $30{ }^{\circ} \mathrm{C}$ and $45^{\circ} \mathrm{C}$, is preferred over thermophilic conditions (Table 4). In a long term experiment fermenting ethanol-rich beer (from a yeast fermentation) in a SBR with in-line product extraction, selectivity for C6 nearly tripled after reducing the temperature from 55 to $30{ }^{\circ} \mathrm{C}[130]$.

The effect of temperature on acidogenesis and VFA production has been studied in more depth and could provide further insight. In a study evaluating acidogenesis of cafeteria food waste, trials at 25,35 and $45{ }^{\circ} \mathrm{C}$ gave the highest overall carboxylic acid yield at $35^{\circ} \mathrm{C}\left(\sim 23.5 \mathrm{~g} \mathrm{~L}^{-1}\right.$ total carboxylic acids with $\sim 3.1 \% \mathrm{C} 6)$, yet the $\mathrm{C} 6$ yield was higher at $45^{\circ} \mathrm{C}\left(\sim 19.8 \mathrm{~g} \mathrm{~L}^{-1}\right.$ total carboxylic acids with $24 \%$ C6) [125]. VFA-targeted fermentation of pre-treated cellulosic biomass with meso- $\left(40{ }^{\circ} \mathrm{C}\right)$ or thermophilic $\left(55^{\circ} \mathrm{C}\right)$ operation showed a significant divergence in the proteins and enzymes present and in MMC composition. Mesophilic operation allowed C6 formation to occur (3 to 4\% of carboxylic acids) while no C6 was found under thermophilic conditions [129,131]. The thermophilic reactor maintained a community similar to the inoculum, rich in Clostridia, while the mesophilic system showed a wider variety of taxa which was dominated by members in the Bacteroidetes phylum [129]. While there are some indications that a mesophilic temperature favours chain elongation, more evidence is needed to understand the processes that affect chain elongation productivity at different temperatures. These could be attributed to changes in the collective microbiome metabolism and/or composition, as well as to thermodynamic and kinetic shifts to competing reactions.

\subsection{The Influence of $\mathrm{pH}$ and Buffer Capacity on MCCA Production}

Metabolic pathways, hydrolysis, thermodynamics and, product outcome are significantly influenced by $\mathrm{pH}$ in MMC fermentation [123]. For example, in fermentation of cheese whey poor control of $\mathrm{pH}$ led to fluctuating carboxylic acid concentrations and hindered establishment of steady state [111]. The specific effects of $\mathrm{pH}$ on chain elongation are not straightforward and various factors must be considered.

Firstly, $\mathrm{pH}$ determines the dissociation/association equilibrium between carboxylic acids and carboxylates, and therefore the impact of product toxicity due to the acidic form. Secondly, $\mathrm{pH}$ determines the $\mathrm{CO}_{2}$ and carbonate distributions, which affects buffer capacity, and its availability to certain organisms. For instance C. kluyveri requires incorporation of $\mathrm{CO}_{2}$ in its biomass [132]. Thirdly, thermodynamic feasibility depends on $\mathrm{pH}$. Indeed, chain elongation is less thermodynamically favourable under alkaline conditions [133]. Lastly, the effect on the microbiome composition and microbial competition has to be taken into account. For instance, the highest reported production rate of $\mathrm{C} 6$ and $\mathrm{C} 8$ was obtained at neutral $\mathrm{pH}$, yet a specific methanogenic inhibitor had to be added since acetoclastic methanogens compete under these conditions, and consume $\mathrm{C} 2$ for $\mathrm{CH}_{4}$ production, reducing its availability for chain elongation [105]. Methanogenesis occurs within a pH range of 6.0-8.3 while acidogenic bacteria can tolerate lower $\mathrm{pH}$ [134]. Thus a strategy to minimize $\mathrm{CH}_{4}$ production is to operate at slight acidic $\mathrm{pH}(5.0-5.5)$, and this has been applied in various VFA or MCCA producing experiments $[100,123,130]$.

The effects of $\mathrm{pH}$ on primary fermentation also have to be considered. Experimental studies have shown that controlling $\mathrm{pH}$ at alkaline or neutral values improved liquefaction and hydrolysis of solids in organic waste, but it did not support chain elongation since short chain carboxylates were accumulated without production of MCCAs [126,135-137]. In addition, it is necessary to consider the cost of $\mathrm{pH}$ correction, as for example, food waste has an average $\mathrm{pH}$ of 5.1 [138]. Operating at neutral 
or alkaline $\mathrm{pH}$ would require substantial addition of $\mathrm{pH}$-correcting chemicals, and hence lower the economic feasibility [89].

Despite the complex effects of $\mathrm{pH}$ on MMC fermentation, some general effects on product outcome are reported for organic or synthetic waste fermentation. A shift to lactic acid or ethanol production was observed in two separate studies, one at $\mathrm{pH}<3.6$ [115] and another at $\mathrm{pH}<4.5$ [139]. At slightly higher $\mathrm{pH}$ range of 5.0 to $5.5 \mathrm{C} 3$ accumulated as main fermentation product [139]. Two studies have investigated the effect of $\mathrm{pH}$ on $\mathrm{H}_{2}$ production, an important element necessary for chain elongation, which found different results: one suggested optimal production around a $\mathrm{pH}$ of 4 [115] and another at $\mathrm{pH}$ of 8 [140]. Finally, MCCA production can occur under slightly acidic conditions $(5<\mathrm{pH}<$ 6), although isolates of MCCA producers such as C. kluyveri operate best at near-neutral pH [106]. Therefore in order to favour chain elongation the evidence so far suggests that whilst the target microbial communities might operate across a broader $\mathrm{pH}$ range, a slightly acidic or neutral $\mathrm{pH}$ might result in the best compromise between thermodynamics, kinetics and microbial competition. The $\mathrm{pH}$ might need optimisation depending on other operational parameters and fermentation characteristics, such as other factors influencing competitive reactions or substrate composition.

\subsection{The Influence of $\mathrm{pH}$ on Product Toxicity}

Another aspect linked with operational $\mathrm{pH}$ is product toxicity from $\mathrm{C} 6$ and $\mathrm{C} 8$ compounds. Carboxylic acids up to a carbon chain length of 18 are potent antimicrobial compounds that interact with lipid bilayers of cell membranes, disrupting the energy generating mechanisms, internal $\mathrm{pH}$, and cell integrity [141,142]. At acidic $\mathrm{pH}$ a higher percentage of MCCAs are present in their un-dissociated, toxic acid form. With a pKa of 4.85 for $\mathrm{C} 6$ and 4.89 for C8, $50 \%$ of the total carboxylate is found in the acidic form at a pH equal to the pKa. $\mathrm{C} 6$ and $\mathrm{C} 8$ showed similar toxicity in E. coli at 10.2 to $14.1 \mathrm{~g}_{\mathrm{COD}} \mathrm{L}^{-1}$ at $\mathrm{pH} 7$ [143]. For mixed culture chain elongation, different inhibitory concentrations have been reported. Angenent et al. [58] observed the inhibitory concentration of protonated C6 to be $1.92 \mathrm{~g}_{\mathrm{COD}} \mathrm{L}^{-1}$ in a system using yeast-fermentation beer. Khor et al. [95] obtained stable C6 production around $\mathrm{pH} 5.5$ at just below this limit during fermentation of grass silage with adapted MMC; however, supplementation of lactic acid led to accumulation of protonated $\mathrm{C} 6$ concentrations up until $4.4 \mathrm{~g}_{\mathrm{COD}} \mathrm{L}^{-1}$, with total $\mathrm{C} 6$ concentrations close to the solubility limit of $\mathrm{C} 6\left(\approx 22.7 \mathrm{~g}_{\mathrm{COD}} \mathrm{L}^{-1}\right)$.

Table 4. Reported environmental conditions to select for chain elongation in MMC fermentation for MCCA production.

\begin{tabular}{|c|c|c|}
\hline & Summarised Literature Findings & Ref. \\
\hline \multicolumn{3}{|c|}{ Temperature } \\
\hline Preference & Mesophilic range from 30 to $45^{\circ} \mathrm{C}$ & {$[49,125,129-131]$} \\
\hline Effect & Indications of influence on microbiome composition. & [129] \\
\hline \multicolumn{3}{|c|}{$\mathrm{pH}$} \\
\hline Preference & Slight acidic: preferred range from $\mathrm{pH} 5$ to 6 & {$[100,123,130,134]$} \\
\hline & Neutral $\mathrm{pH}$, if specific methanogen inhibitors added & {$[105,106]$} \\
\hline Self-regulation & $\begin{array}{l}\text { Without control, } \mathrm{pH} \text { usually stabilises between } 5.5 \text { and } 6.7 \\
\text { Protonated C6 toxicity limit: } 1.92 \mathrm{~g}_{\mathrm{COD}} \mathrm{L}^{-1}\end{array}$ & {$[90,95,135]$} \\
\hline Product toxicity & $\begin{array}{c}\text { C6 accumulation over toxicity limits is possible (in batch, } \\
\text { one point measurement) }\end{array}$ & {$[37,58,95]$} \\
\hline \multicolumn{3}{|c|}{ Alkalinity } \\
\hline MCCA & No data available & \\
\hline $\mathrm{AD}$ & 1 to $5 \mathrm{gCaCO}_{3} \mathrm{~L}^{-1}$ & {$[144,145]$} \\
\hline $\mathrm{H}_{2}$ & $0.11 \mathrm{gCaCO}_{3} \mathrm{~L}^{-1}$ & [146] \\
\hline VFA & 2.4 to above $30 \mathrm{gCaCO}_{3} \mathrm{~L}^{-1}$ & {$[122,147,148]$} \\
\hline
\end{tabular}

\subsection{Buffering Capacity and Potential of Self-Regulation of $\mathrm{pH}$}

The buffering capacity or alkalinity of the fermentation broth is the capacity to neutralize acids via the presence of compounds such as phosphate, bicarbonate, carbonate and hydroxides. If there is limited buffer capacity or no continuous $\mathrm{pH}$ control, the $\mathrm{pH}$ in $\mathrm{MMC}$ fermentation quickly drops 
to minimum of 3.0 due to acidification [140,149]. Fermentation of Brewer's Spent Grain was shown to reduce $\mathrm{pH}$ from 6.5 to 3.8 after only 1 day due to lactic acid production [133]. Also ammonium $\left(\mathrm{NH}_{4}{ }^{+}\right)$released during hydrolysis of nitrogen-rich feedstock neutralises acids during fermentation by anaerobic consortia [150]. Sometimes chain elongation experiments include a buffer in their synthetic medium [127]; alternatively bicarbonate is added as nutrient requirement for $C$. kluyveri $[72,74,110]$.

No studies could be found that evaluate the effect of alkalinity on chain elongation. However, for other types of MMC fermentation alkalinity and buffering mechanisms have been studied (Table 4). Examples include $\mathrm{AD}, \mathrm{H}_{2}$ production or acidogenesis for VFA production, which sometimes include the reporting of $\mathrm{C} 6$. Alkalinity in MMC fermentation in AD is well studied and its measurement serves as a tool to indicate early warning of unwanted acidification and $\mathrm{pH}$ destabilisation [151]. The optimal value of alkalinity usually lies between $1.0-5.0 \mathrm{~g}_{\mathrm{CaCO} 3} \mathrm{~L}^{-1}$ [144,145]. For $\mathrm{H}_{2}$ production by MMC from organic waste, an alkalinity optimum was found around $0.11 \mathrm{~g}_{\mathrm{CaCO} 3} \mathrm{~g}_{\mathrm{COD}}{ }^{-1}$ with excessive alkalinity resulting in increased osmotic pressure [146]. Improved VFA production has been noted for fermentation reactors processing cheese whey, the organic fraction of municipal solid waste or synthetic soft drink wastewater with higher alkalinity ranging from 2.4 to above $30 \mathrm{~g}_{\mathrm{CaCO}_{3}} \mathrm{~L}^{-1}[122,147,148]$. Comparison of buffered $(\mathrm{pH} \approx 7)$ and unbuffered ( $\mathrm{pH}$ drop to approx. 6) batch fermentation of vegetable and salad waste over 70 days showed that addition of $\sim 13.3 \mathrm{~g} \mathrm{~L}^{-1} \mathrm{NaHCO}_{3}$ tripled $\mathrm{C} 6$ concentrations for the first 52 days to a maximum of $6.6 \mathrm{gCOD}^{-1}$. However, over longer operating times production decreased in the buffered system due to methanogenesis resulting in similar $\mathrm{C} 6$ yield for the two systems at the end of operation [126]. Therefore, there are indications that a minimum alkalinity would benefit MCCA production, but this needs to be further investigated.

Studies aimed at VFA production from complex substrates indicate a self-regulation of $\mathrm{pH}$ in MMC fermentation in the range of 5.2 to 6.7 [135]. A similar $\mathrm{pH}$ stabilisation effect has been noted by studies directed at MCCA formation. For example, batch fermentation of food waste generated a $\mathrm{pH}$ drop from 7 to $\sim 5.3$ due to hydrolysis and primary fermentation; after 20 days it rose again to $\mathrm{pH} 5.8$ with production of MCCAs [90]. For continuous processes this effect results in an overall $\mathrm{pH}$ stabilisation. A stable $\mathrm{pH}$ between 5.5 and 6.2 occured while feeding a lactic-rich substrate at $\mathrm{pH} 4.5$ to 5 [95]. Chain elongation via lactic acid consumes protons (Table 1, Equations (7)-(9)), although no studies have investigated the link between lactic acid-mediated elongation and the buffering of $\mathrm{pH}$. Further studies are needed to show the minimal alkalinity required for chain elongation in MMC to sustain a minimum buffer capacity, which also allows continuous operation at optimal $\mathrm{pH}$, and with limited or no $\mathrm{pH}$ control.

\section{The Push towards Chain Elongation by Organic Overloading}

For AD applications, organic overloading is defined as the COD loading rate exceeding the degradation capacity of the anaerobic microbiome, leading to accumulation of VFAs and hence a decrease of $\mathrm{pH}$ which inhibits methanogens [152]. For VFA and MCCA production, organic overloading is deliberately employed to promote carboxylic acid accumulation and limit competitive processes. Elevated carboxylic acid concentrations inhibit methanogens, as found, for instance, for $\mathrm{C} 4$ where only $\sim 2.4 \mathrm{~g}_{\mathrm{COD}} \mathrm{L}^{-1}$ at pH 6 was shown to inhibit $90 \%$ of methanogens in a thermophilic batch fermentation [130].

The organic load at start-up can be represented by the food-to-microorganisms ratio (F/M). This is defined as the amount of feedstock introduced, expressed as COD or volatile solids (VS), relative to the amount of biomass, estimated as VS or volatile suspended solids (VSS) in the inoculum $[9,153]$. In anaerobic consortia fermenting food waste, organic overloading and VFA accumulation usually occur at start-up with a $\mathrm{F} / \mathrm{M}$ ratio $>1 \mathrm{gCOD}_{\text {fed }} \mathrm{gVS}_{\text {inoculum }}{ }^{-1}$ and carboxylates accumulate at an optimal F/M ratio of $5 \mathrm{gCOD}_{\text {fed }} \mathrm{gVS}_{\text {inoculum }}{ }^{-1}$ [9]. As with the acidogenic fermentation of synthetic soft drink wastewater, a F/M ratio of $4.0 \mathrm{gCOD}_{\text {fed }} \mathrm{gVSS}_{\text {inoculum }}{ }^{-1}$ was found to be optimum for C6 production compared to $\mathrm{F} / \mathrm{M}$ ratios of either 1.6 and $6.4 \mathrm{gCOD}_{\text {fed }} \mathrm{gVSS}_{\text {inoculum }}{ }^{-1}$ [148].

A positive relationship is found for MCCA production and higher organic loading rates (OLRs) using synthetic or supplemented substrates and pure cultures or MMC [96]. However, for complex 
feedstock, whilst the same mechanism would be expected, the relationship between OLR and MCCA production is less straightforward (Figure 3). When using a synthetic medium or supplementation of electron donors the OLR, expressed in terms of total COD, is directly related to the amount of bio-available substrate. On the contrary, when using complex feedstock, the OLR does not necessarily indicate the presence of chain elongation substrates or anaerobic biodegradable content, which can be converted to chain elongation compounds. Namely, fractions can be present in complex feedstocks that can be chemically oxidised, and thus contribute to the total COD, but are not easily biologically degraded. For instance, bio-waste collected from municipalities had a higher anaerobic biodegradability $(90.8 \pm 3.7 \%)$ compared to food waste collected from a vegetarian restaurant $(66.9 \pm 6.4 \%)$ even though their total COD values were within a similar range, i.e., $337 \pm 14 \mathrm{~g}_{\mathrm{COD}} \mathrm{kg}_{W W}{ }^{-1}$ and $303 \pm 18 \mathrm{~g}_{\mathrm{COD}} \mathrm{kg}_{W W}{ }^{-1}$ respectively [17]. MMC fermentation experiments for MCCA products using complex feedstocks have only recently been conducted, and little is known regarding the need for easily biodegradable feedstock in order to exert sufficient OLR to accumulate chain elongation substrates for $\mathrm{C} 6$ production. In $\mathrm{AD}$, high-COD substrates such as food waste or food processing by-products result in problematic increased retention times and low throughput, to prevent organic overloading and hence such feedstocks show greater potential for production of MCCAs rather than biogas.

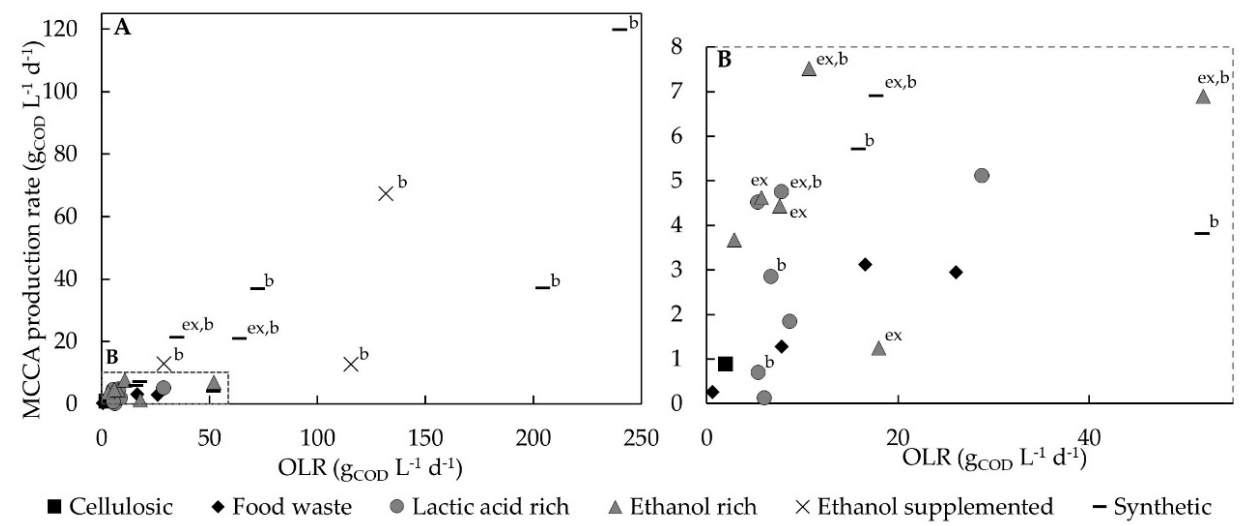

Figure 3. The highest reported MMCA (C6 to C9) production rate as a function of OLR and type of feedstock from 27 different studies using (semi-)continuous MMC fermentation towards MCCAs, VFAs or $\mathrm{H}_{2}$. Experiments including in situ product removal or biomass retention are marked with "ex" or "b", respectively. Studies using complex feedstock are only included which report production rates and OLR in gCOD $^{-1}$, or where such values can be estimated using calculations described in Appendix A. Studies using synthetic substrates only include those listed in Table 3, and three additional studies which used synthetic media comprising ethanol and C2 to represent highest reported rates with HRT optimisation [72,105] and in situ extraction [96] respectively. Data collected from $[23,27,36,37,72,77,88$, $91-97,100,105,106,110,111,115,116,123,125-128,154]$, the full data for the figure can be consulted in the following database [55].

\section{Effect of Inoculum on Achieving MCCA}

Selection of the appropriate inoculum in biotechnological applications is critical to ensure catalysis of the required bio-conversion process. Cultures used for inoculating reactor experiments with complex substrates for carboxylate production contain a large variety of microorganisms (high richness) and include anaerobic sludges from $\mathrm{AD}$ [147] or wastewater treatment [133], marine sediments [107,129], rumen samples [30,40], mixtures of cultures [155] or microbiomes enriched in chain elongators obtained from lab-scale reactors $[83,91,96]$. For production of VFAs, $\mathrm{H}_{2}$ or other MMC fermentation products, the inoculum can be physico-chemically pretreated in order to suppress methanogenesis, e.g., heat shock and/or acid/alkali conditioning [156,157]. However, no studies could be found on the effect of inoculum pretreatment on MCCA production specifically. Studies on MMC fermentation towards $\mathrm{H}_{2}$ or VFAs have shown that the microbial composition was altered 
and the MMC fermentation product profile shifted depending on inoculum pretreatment method applied [7,47,158,159]. For chain elongation in particular, Cavalcante et al. [69] has discussed thermal pretreatment as a potential selective pressure since various chain elongating bacteria have been allocated to the genus Clostridium, that due to its spore-forming abilities could be selected for by heat shock. The limited knowledge regarding pretreatment of inoculum to select for chain elongation would be worthwhile to further investigate.

Separate inoculation is not always required. Some experiments showed C6 production from organic waste by simply using the endogenous MMC present in the feedstock [108,135]. In addition, regardless of the initial inoculum source (i.e., sludge from full-scale AD plant or lab-scale fermentation reactors) microbiomes grown on synthetic substrates with ethanol as the main electron donor are enriched by species closely related to C. kluyveri due to adaptation over time [70,101].

As shown in Figure 4, for batch experiments, the most commonly used inoculum types are AD sludge or enriched microbiomes, i.e., previously enriched and adapted to chain elongation conditions in the lab. Yields seem to be similar for both types of inoculum, perhaps due to high microbial richness. However, the total MCCA concentration accumulated with an AD inoculum had a 5 times lower upper range than when an adapted microbiome is used, indicating that tolerance towards toxic MCCA concentrations can be developed (Figure 4).

This tolerance to higher C6 concentrations from acclimatised microbiomes has been recently reported using batch inhibition assays with synthetic media and differently cultured sludges [160]. The same adaptability hypothesis was used to explain productions of longer MCCA such as C8 [92]. However, batch experiments inoculated with an enriched microbiome are often operated at a higher organic load that could also enhance MCCA accumulation, and these parameters are inter-connected. From the analysed studies it also appears that bio-augmentation does not improve considerably the MCCA yields, but it does impact on the product concentration with more MCCAs produced. It has been shown that bio-augmentation with $C$. kluyveri improves yields and even results in chain elongation up to decanoic acid (C10) [90]. From the data currently available, inoculum selection could contribute to MCCA specificity, yet further investigations are needed to evaluate the importance of inoculum selection.

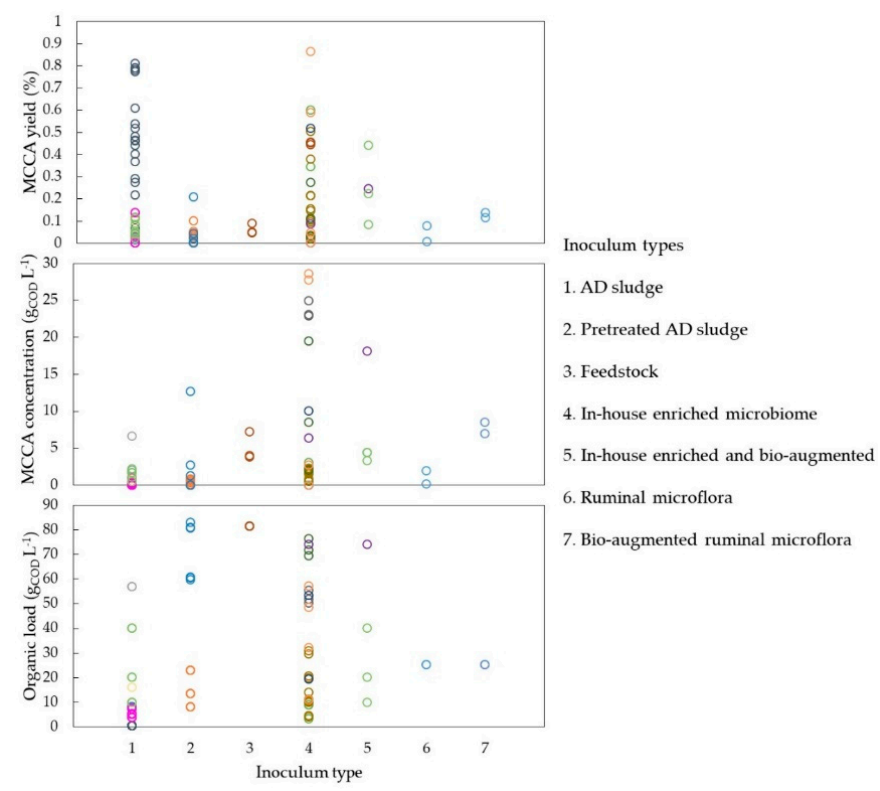

Figure 4. Inoculum type used in 17 studies performing batch experiments of complex or synthetic feedstock in function of the obtained MCCA yield (top), MCCA concentration (middle), or organic load applied (bottom). Colours represent experimental results reported in the same study. Estimated values were calculated as reported in Appendix A. Data collected from [20,40,70,83,88,90,91,96,101,108, $122,126,148,157,161-163]$, the full data for the figure can be consulted in the following database [55]. 


\section{The Influence of Partial Pressures in Reactor Headspace}

\subsection{The Aerotolerance of MMC Fermentation}

M. elsdenii and C. kluyveri, two well-characterised bacteria capable of chain elongation, are both strictly anaerobic [61,132]. Anaerobic conditions are easily maintained in laboratory experiments by flushing the headspace with $\mathrm{N}_{2}, \mathrm{CO}_{2}$ or $\mathrm{H}_{2}$ or mixtures thereof. However, full-scale or pilot reactors are not always operated fully anaerobically [164]. Therefore, it is important to understand the sensitivity to the presence of oxygen on MMC when producing MMCAs.

In a study investigating the aerotolerance of MMC fermentation of shredded paper and chicken manure, intermittent air exposure had no significant influence on bacterial community composition, however, it did select for shorter chain carboxylates, whilst stricter anaerobic conditions improved chain elongation [164]. On the contrary, in another study using different types of pre-treated corn fibre, air exposure did not lower the C6 production rate [36]. There is still very little evidence of the capacity of MMC cultures performing chain elongation in regards to their tolerance of oxygen and its impact on the production of MMCAs. This should be the subject of further studies as it is an important design parameter for experimental and full-scale chain elongation processes.

\subsection{Minimal and Balanced $\mathrm{CO}_{2}$ and $\mathrm{H}_{2}$ Required for Chain Elongation}

A sufficiently high $\mathrm{H}_{2}$ partial pressure $\left(\mathrm{pH}_{2}\right)$ in the headspace gas is an important parameter to limit the impact of competitive processes and is seen as a central strategy to ensure reductive conditions for reverse $\beta$-oxidation [130]. However, the mechanism of how $p \mathrm{H}_{2}$ affects chain elongation is not fully understood, and various values have been reported (Table 5). Similarly, $p \mathrm{H}_{2}$ controls the VFA yielding of anaerobic MMC fermentation such as AD. Different $p \mathrm{H}_{2}$ have been reported to inhibit or thermodynamically constrain certain bioconversion processes thereby influencing the VFA product spectrum $[165,166]$.

In thermodynamic fermentation models, it is assumed that dissolved $\mathrm{H}_{2}$ affects the $\mathrm{NADH} / \mathrm{NAD}^{+}$ ratio directly, and hence the thermodynamic feasibility of certain pathways [81]. Nevertheless, experimental work could not find a direct correlation between the two, thus possibly indicating a more complex effect where alternative electron carriers (e.g., ferrodoxin) are involved in MMC [167]. $\mathrm{H}_{2}$ is a product from ethanol- and lactic acid oxidation occurring during chain elongation [29], yet it is also an indirect electron donor for chain elongation by its capability of reducing C2 to ethanol [127]. A minimum $\mathrm{pH}_{2}$ (a composition $>0.007 \%$ at standard conditions) was found to prevent excessive oxidation of ethanol (i.e., ethanol oxidation to $\mathrm{C} 2$ not coupled to chain elongation) or oxidation of carboxylates [37,98]. In batch microbiome studies using synthetic C2-rich media, C6 and C8 were only produced in the presence of $\mathrm{H}_{2}$, even in the absence of ethanol $[70,91]$. If $\mathrm{pH}_{2}$ is too high, carboxylates are reduced to their corresponding alcohol [168]. In addition, a $p \mathrm{H}_{2}$ above $\sim 0.1$ bar reduces the thermodynamic favourability of ethanol oxidation to C2 for ATP generation [58,81]. In general, it is stated that the $\mathrm{pH}_{2}$ should be above $\sim 0.03$ bar to avoid excessive ethanol oxidation to C2 while remaining below $\sim 1.5$ bar to prevent carboxylate reduction [106] (Table 5).

Another important headspace component is $\mathrm{CO}_{2}$. With a MMC membrane biofilm reactor MCCA were produced solely from a 40/60 ratio of $\mathrm{CO}_{2}$ and $\mathrm{H}_{2}$ [169]. $\mathrm{CO}_{2}$ is also a nutritional requirement for some chain elongating bacteria [132]. In addition, $\mathrm{CO}_{2}$ partial pressure influences dissolved carbonate and thus the alkalinity. Experimental studies have shown $\mathrm{CO}_{2}$ addition in the headspace improved chain elongation [105], and a combination of $\mathrm{CO}_{2}$ and $\mathrm{H}_{2}$ in the reactor headspace reduced $\mathrm{C} 3$ formation [117]. $\mathrm{CO}_{2}$ dosing within the reactor headspace was recently proposed as a key strategy in controlling ethanol-based chain elongation, where high $\mathrm{CO}_{2}$ loading rates for ethanol-rich feedstock could stimulate excessive ethanol oxidation to $\mathrm{C} 2$, and low values for VFA-rich (and low-ethanol) feedstock could ensure ethanol is used in chain elongation and not for C2 production [98]. Dosing of $\mathrm{CO}_{2}$ is inversely proportional to the $p \mathrm{H}_{2}$, thus care must be taken to ensure 
minimal $p \mathrm{H}_{2}$. Weimer et al. [30] calculated the $\mathrm{H}_{2}: \mathrm{CO}_{2}$ ratio that shows the optimal thermodynamics for chain elongation and suggested approx. 1 bar $p \mathrm{H}_{2}$ with 0.3 bar $p \mathrm{CO}_{2}$.

Using a complex feedstock will lead to production of $\mathrm{CO}_{2}$ and $\mathrm{H}_{2}$, since they are both products of primary fermentation by various hydrolytic and acidogenic microorganisms [170]. Therefore, modifying the headspace composition by allowing these gases to accumulate in batch operation in closed vessels [83], working with pressure release in reactors [133] or intermittent opening of reactor headspace for sampling [148], is expected to affect chain elongation. This effect is usually not taken into account in experiments, and to our current knowledge, no studies have specifically assessed the effect of accumulation of these gases in the reactor headspace during primary fermentation on chain elongation. The partial pressure of gases in the reactor headspace should be considered in the design and operation of reactors as plenty of studies demonstrate their influence on chain elongation. However, it must be noted that $\mathrm{H}_{2}$ is a highly soluble gas and its concentration in the liquid can be up to 70 times higher than the equilibrium value suggested from mass-transfer coefficients in AD [171]. Therefore, care must be taken to relate $p \mathrm{H}_{2}$ with $\mathrm{H}_{2}$ available for bioconversion processes.

Table 5. Experimental and theoretical reported values of $p \mathrm{H}_{2}$ and/or $p \mathrm{CO}_{2}$ in reactor headspace to stimulate chain elongation in MMC fermentation.

\begin{tabular}{|c|c|c|}
\hline Headspace Requirement & Influence on Chain Elongation & Ref. \\
\hline \multicolumn{3}{|c|}{ Hydrogen } \\
\hline$p \mathrm{H}_{2}<0.1$ bar & $\begin{array}{l}\text { Theoretical maximum } p \mathrm{H}_{2} \text { for oxidation of ethanol to } \mathrm{C} 2 \text { for } \\
\text { ATP generation to be thermodynamically feasible }\end{array}$ & [58] \\
\hline$p \mathrm{H}_{2}<1.5$ bar & $\begin{array}{l}\text { Experimental } p \mathrm{H}_{2} \text { minimum to trigger reduction of } \mathrm{C} 2, \mathrm{C} 3 \text { and } \\
\qquad \mathrm{C} 4 \text { to alcohols }(\mathrm{pH}=5)\end{array}$ & {$[168]$} \\
\hline$p \mathrm{H}_{2}=1.5 \mathrm{bar}$ & Initiated production of $\mathrm{C} 6$ from ethanol and $\mathrm{C} 2$ in experiment & [70] \\
\hline$p \mathrm{H}_{2}>2.52 \times 10^{-6}$ bar & $\begin{array}{c}\text { Theoretical minimum } p \mathrm{H}_{2} \text { to prevent oxidation of } \mathrm{C} 6 \text { at } \\
\text { experimental concentrations }\end{array}$ & [37] \\
\hline 0.03 bar $<p \mathrm{H}_{2}<1.5$ bar & Recommended $p \mathrm{H}_{2}$ for chain elongation & {$[106]$} \\
\hline \multicolumn{3}{|c|}{ Carbon Dioxide } \\
\hline $\mathrm{CO}_{2}$ or $\mathrm{CO}_{3}^{2-}$ addition & Lowered $\mathrm{pH}$, improved MCCAs production & {$[105]$} \\
\hline \multicolumn{3}{|c|}{ Mixture of Hydrogen and Carbon Dioxide } \\
\hline$p \mathrm{H}_{2} \approx 0.007 \%$ by dosing $\mathrm{CO}_{2}$ & Excess oxidation is thermodynamically prevented & [98] \\
\hline $\mathrm{H}_{2} / \mathrm{CO}_{2}=60 / 40$ & MCCAs produced from $\mathrm{H}_{2} / \mathrm{CO}_{2}$ mixture & [169] \\
\hline $\mathrm{H}_{2} / \mathrm{CO}_{2}=80 / 20$ at 0.5 bar & Enhanced production of $\mathrm{C} 6$ from ethanol and $\mathrm{C} 2$ in experiment & [91] \\
\hline$p \mathrm{H}_{2}=2$ bar, $p \mathrm{CO}_{2}=2$ bar & Reduced C3 formation & {$[117]$} \\
\hline$p \mathrm{H}_{2}=1$ bar, $p \mathrm{CO}_{2}=0.3$ bar & Optimal thermodynamics for chain elongation & [30] \\
\hline
\end{tabular}

\section{Reactor Design and the Relation to Retention and Organic Overload}

The type of feedstock will influence the choice of fermentation reactor [8]. In the case of a complex, solid-rich feedstock, such as OFMSW or unprocessed food waste, hydrolysis is rate limiting and stirring or pumping is impractical. Therefore, longer retention times are required to allow hydrolysis and solubilisation, and leach bed reactors (LBRs) are an effective option, as they generate a leachate rich in carboxylic acids. For instance, Yesil et al. [172] obtained $\pm 30 \mathrm{gCOD}$ of carboxylic acids per kg of solid waste of which approx. $10 \%$ was C6, in batch LBR. Nzeteu et al. [91] used a LBR set-up that allowed semi-continuous operation and obtained a maximum $\mathrm{C} 6$ production rate $\left(3.12 \mathrm{~g}_{\mathrm{COD}} \mathrm{L}^{-1} \mathrm{~d}^{-1}\right)$ from food waste by replacing $75 \%$ of the reactor content with fresh feedstock and diluting the leachate with water by $1 / 15$ every 7 days. However, this approach does not easily allow operation with homogenous $\mathrm{pH}$ or temperature stability. Another study has shown that operation stability for the production of $\mathrm{H}_{2}$ by MMC fermentation of food waste is enhanced by mixing and agitation [116], however, this has not yet been determined for chain elongation.

To exert better process control, complex feedstock can be mechanically pre-treated, i.e., crushing, chopping or blending, to obtain a mixture that can be pumped and stirred, and therefore allows the use of (semi-)continuous stirred tank reactors (sCSTRs). This has been done in some studies focussing on carboxylic acid production from food waste $[125,126]$. In addition, the feed stream can be diluted with water, or blended with a liquid waste stream or recycled liquor from sludge dewatering to modify the 
composition. For a more fluid stream such as synthetic feedstock, e.g., ethanol and acetate mixtures, or more easily degradable substrates such as potato-processing or brewery wastewater or food waste leachate, less hydrolysis is required and the chain elongation itself becomes rate-limiting. To allow higher flow rates, whilst maintaining high biomass to counter the rate-liming effect of chain elongation, reactor configurations such as membrane bioreactors [169], CSTRs with in situ settlers [128] and up-flow reactors (UR) with mechanisms for biomass retention, e.g., filter, sludge blankets or packed beds, have been used (Table 3). It has been suggested that biomass retention and cell density are important parameters which are often unreported for MMC fermentation [95]. Indeed, studies using reactors with biomass retention have shown the highest MCCAs production rates so far (Figure 3). Such reactors are well established for other processes, and are worthy of investigation.

In continuous systems, the inoculum acclimation and biomass retention, also expressed as sludge retention time (SRT), favour specific microbial populations. For instance, C4 producers have often been shown to have a longer doubling time than lactic acid producers, and hence wash out more easily from continuous systems [47]. In stirred tank reactors without a settling phase, the SRT is equal to the hydraulic retention time (HRT) and inversely proportional to the OLR. Therefore, in order to operate at a sufficient biomass retention, the OLR can only increase with an increase of substrate COD composition. A suboptimal residence time results in lactic acid or VFA accumulation without chain elongation, and a reduction in hydrolysis $[97,128]$. In fermentation of salad and vegetable waste in a sCSTR, a retention time of 10 days left a fraction of the substrate unutilized and no C6 was produced; whilst retention time of 20 and 30 days increased C6 production [126]. Similarly, a step-wise decrease of HRT from 20 to 12 to 8 days in cheese whey fermentation, generated C6 concentrations which decreased from $2.24 \mathrm{gCOD}^{-1}$ to $1.45 \mathrm{gCOD}^{-1}$ to $0.41 \mathrm{gCOD}^{-1}$. Analysis of the microbiome composition revealed certain microbial groups were removed by lowering the HRT, via washout, with a dominant presence of lactic acid-producing Lactobacillus sp. at HRT of 8 days [123]. Thus, a minimum HRT is required to sustain chain elongation when working with reactors without biomass retention. However, if the HRT is too high competing processes such as methane production are more favoured [36,126]. Methanogens are relatively slow growers, thus reducing HRT has been suggested as a tactic to wash them out, and increase MCCA production rates [72,106]. Therefore, a compromise to reduce methanogens and enhance chain elongation must be found.

Studies on chain elongation have varied HRT from less than 1 day to over 2 weeks resulting in various MCCA production yields (Figure 5). A lower HRT can generate similar yields by altering reactor design to include biomass retention and hence decoupling the HRT from the SRT. Using an UR with biomass retention, chain elongation was performed using a HRT of only $4 \mathrm{~h}$, resulting in a maximum MCCA production rate of $57.4 \mathrm{~g} \mathrm{~L}^{-1} \mathrm{~d}^{-1}$ using a synthetic ethanol and C2 feed supplemented with methanogenic inhibitors, yeast extract and $\mathrm{CO}_{2}$ at neutral $\mathrm{pH}$ [105]. In addition, increasing HRT reduces product toxicity by eliminating accumulation, e.g., by gradually reducing HRT from 20 to 2.5 days C6 production from cheese whey rate increased to $\sim 5 \mathrm{gCOD} \mathrm{L}^{-1} \mathrm{~d}^{-1}$ [100].

It is important to note that other operational factors come in to play alongside HRT. For instance, increasing HRT from 8 to 12 days and operating at $35{ }^{\circ} \mathrm{C}$ increased $\mathrm{C} 6$ concentrations in food waste fermentation from approx. $1.64 \mathrm{gCOD}^{-1}$ to $6.55 \mathrm{gCOD}^{-1}$, and even more $\mathrm{C} 6\left(10.26 \mathrm{gCOD}^{-1}\right) \mathrm{was}^{\mathrm{C}}$ obtained at a HRT of 8 days by operating at $45{ }^{\circ} \mathrm{C}$ [125]. Therefore, the optimal HRT to stimulate chain elongation in complex feedstock fermentations will vary according to the type of system used, as it strongly depends on the reactor configuration, hydrolysis rate, sludge retention time, and other operational parameters such as $\mathrm{pH}$ and temperature. 


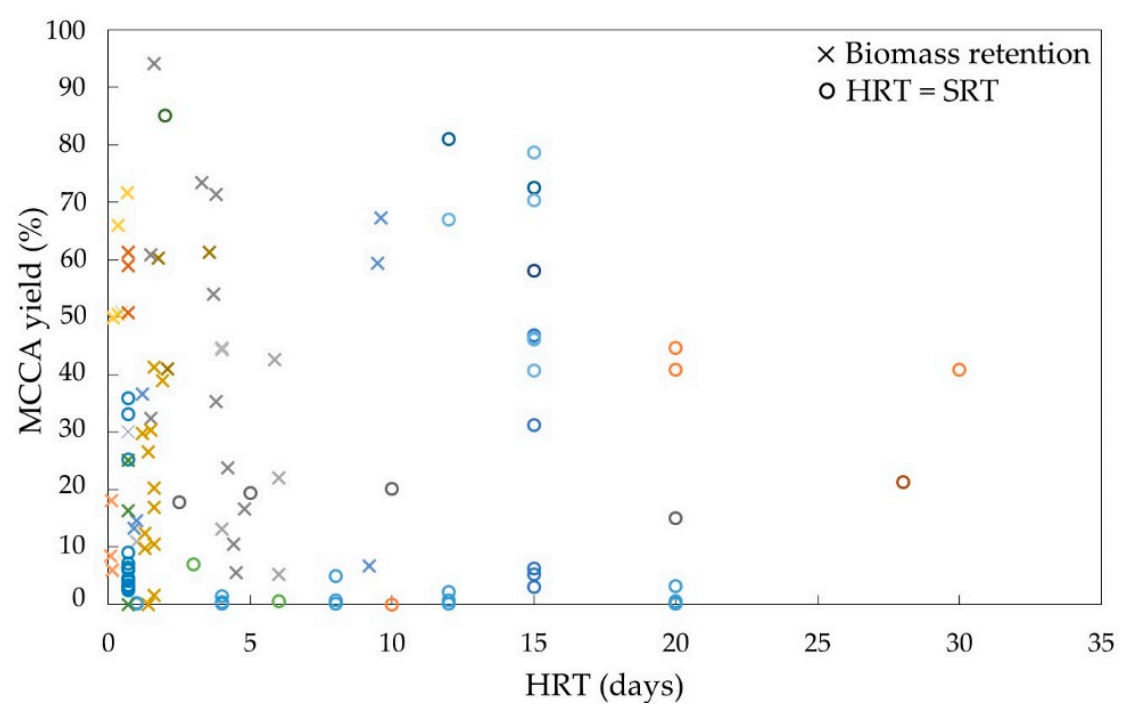

Figure 5. MCCA yield as a function of HRT in 24 studies performing (semi-)continuous experiments of complex or synthetic feedstock. Colours represent experimental results reported within the same study. Estimated values were calculated as reported in Appendix A. Data collected from $[23,27,36,37,72,77$, $88,93-98,100,105,106,110,111,115,123,126-128,173]$, the full data for the figure can be consulted in the following database [55].

\section{Overcoming Product Toxicity by In Situ Extraction, Biofilm Formation or Acclimation}

Low MCCA concentrations in the fermentation broth result in poor product recovery and high cost of down-stream processing. MCCA concentration can be limited in MMC fermentation for three reasons: (i) the substrate is poor in electron donors or in easily biodegradable organics, and hence prevents in situ substrate accumulation to drive chain elongation; (ii) product accumulation lowers the thermodynamic favourability of chain elongation; and (iii) the antimicrobial properties of MCCAs in their protonated state can result in product toxicity. To evaluate which cause is limiting MCCA production, Weimer et al. [40] measured residual substrate and product concentrations and calculated $\Delta \mathrm{G}$ for $\mathrm{C} 6$ production. Incomplete substrate consumption in their MMC fermentation study enriched with $C$. kluyveri and ethanol-supplemented lignocellulosic feedstock still gave a negative $\Delta G$, thus suggesting product toxicity and/or limited incubation time had prevented further MCCA production [40]. Toxicity limits can be offset by employing in situ extraction, or biofilm formation and/or acclimation of the MMC.

In situ extraction methods have the advantage of continuously removing carboxylic acids from the fermentation broth, thereby alleviating product toxicity and thermodynamic constraints [130]. Various in situ extraction systems for carboxylic acids have been proposed for pure culture and MMC fermentation (Table 6). Electrochemical extraction has been applied to recover $\mathrm{C} 2$ to $\mathrm{C} 6$ from stillage fermentation, and has shown to simultaneously control $\mathrm{pH}$ and stimulate chain elongation by $\mathrm{OH}^{-}$ and $\mathrm{H}_{2}$ production at the cathode [23]. However, for MMC fermentation of a complex substrate, a MCCA-selective extraction method is preferred to maintain low MCCA concentrations, whilst VFAs remain in the fermentation broth as substrates for chain elongation. Pertraction has been used in various MMC studies as an in situ extraction method selective for MCCA. This is an in-line liquid-liquid, membrane-assisted extraction method driven by a $\mathrm{pH}$-gradient, and is usually performed with mineral oil containing a phase transfer catalyst, e.g., TOPO, and an alkaline recovery phase $[37,77,93,96,130]$. Pertraction can be combined with membrane electrolysis to drive further separation and obtain a MCCA-rich oil [174]. Whilst the majority of in situ extraction studies report enhanced production rates and chain elongation, two studies did not report a significant improvement $[62,155]$. The advantages of implementing in situ extraction systems must outweigh the increased complexity and cost in process operation. 
Recently, different strategies to overcome product toxicity have been suggested. Allowing biofilms and microscale aggregates to develop improves interactions within a microbiome and tolerance to toxic compounds [175]. Addition of $2 \mathrm{~g} \mathrm{~L}^{-1}$ biochar to a UR fed with synthetic ethanol and C2 significantly improved MCCA production and reduced by-product formation [102]. In this case, microscopic observations revealed the community structure and the spatial distribution of microorganisms changed to dense microbial aggregates around the biochar; it was postulated this improved cell-cell interactions and energy efficiency via stabilising relationships between trophic partners, and increased tolerance to product toxicity [102]. Formation of microbial aggregates has been noted for bioreactors without providing a specific means of biofilm formation; granules were formed in a C3 and ethanol fed CSTR producing C7 as chain elongation product [173]. Therefore, reactor configuration and feedstock that allow microbial aggregates are expected to improve chain elongation, yet research on this is limited. In addition, recent research found the MCCA concentration in the fermentation broth influenced the microbial community structure. It has been suggested that elevated C6 and C 8 concentrations lead to a more acclimatized and resistant MMC $[92,169]$. A microbiome adapted to operating at elevated C6 concentrations had a 10 times higher productivity in an environment with elevated C6 (33 g COD $^{-1}$ ) [160]. Further development of a resistant, highly productive MMC would allow accumulation of MCCA resulting in less complex extraction methods with reduced economic burden due to downstream processing.

Table 6. Overview of the results of applying in situ extraction in MCCA fermentation experiments.

\begin{tabular}{|c|c|c|}
\hline In Situ Extraction and Fermentation Method & Results & Ref. \\
\hline \multicolumn{3}{|c|}{ Biphasic Extractive Fermentation } \\
\hline M. elsdenii strain, sucrose substrate & $58.5 \mathrm{~g}_{\mathrm{COD}} \mathrm{L}^{-1} \mathrm{C} 6$ in solvent & [176] \\
\hline Clostridium $s p$. BS-1, galactitol substrate & $70.6 \mathrm{~g}_{\mathrm{COD}} \mathrm{L}^{-1} \mathrm{C} 6$ in solvent & {$[177]$} \\
\hline \multicolumn{3}{|c|}{ Anion Exchange Resin } \\
\hline M. elsdenii strain, glucose substrate & Extraction doubled C6 to $24.3 \mathrm{~g}_{\mathrm{COD}} \mathrm{L}^{-1}$ & {$[178]$} \\
\hline \multicolumn{3}{|c|}{ Integrated Cross-Flow Nanofiltration } \\
\hline MMC, pre-treated cellulosic feedstock & $\begin{array}{l}7 \times \text { lower carboxylic acid concentration in } \\
\text { fermenter, no significant yield improvement }\end{array}$ & [155] \\
\hline \multicolumn{3}{|c|}{ Membrane Electrolysis } \\
\hline MMC, thin stillage feedstock & $\begin{array}{l}\text { Lower need for caustic soda addition, C4-C6 } \\
\text { from } 46 \% \text { to } 70 \% \text {, cathodic } \mathrm{H}_{2} \text { formation }\end{array}$ & [23] \\
\hline \multicolumn{3}{|c|}{ Pertraction } \\
\hline MMC, diluted yeast fermentation beer & $\begin{array}{l}\text { MCCA-specific, } 4 \times \text { increase in C } 6 \text { specificity to } \\
32 \% \text {, elongation to C } 8 \text {, extraction optimization }\end{array}$ & {$[37,93,130]$} \\
\hline MMC, Synthetic substrate with C2 and ethanol & $4 \times$ increase $\mathrm{C} 8$ productivity to $0.8 \mathrm{~g}_{\mathrm{COD}} \mathrm{L}^{-1} \mathrm{~d}^{-1}$ & [96] \\
\hline MMC, Synthetic substrate with C4 and lactic acid & $\begin{array}{c}\text { Productivity from } 0.6 \text { to } 1 \mathrm{~g}_{\mathrm{COD}} \mathrm{L}^{-1} \mathrm{~d}^{-1} \mathrm{C} 6 \text { by } \\
\text { implementing extraction }\end{array}$ & [77] \\
\hline C. kluyveri, synthetic substrate with C2 and ethanol & No significant difference in production rates & [62] \\
\hline \multicolumn{3}{|c|}{ Pertraction and Membrane Electrolysis } \\
\hline MMC, diluted fermentation beer & $\begin{array}{l}\text { Lower need for caustic soda addition, MCCA } \\
\text { recovery of } 87 \% \text {, obtained }>90 \% \text { MCCA oil }\end{array}$ & [174] \\
\hline
\end{tabular}

\section{MMC Fermentation Scale up and Integration within a Bio-Refinery Context}

Biological MCCA production is mostly in the experimental phase, but some scale-up has also been studied. For example, Hegner et al. [101] showed MCCA-producing MMC can be scaled up from $0.11 \mathrm{~L}$ serum bottles to $2.2 \mathrm{~L}$ bioreactors by maintaining similar reactor operation and without loss of performance or a change in microbial composition. Pilot scale projects are now being started. For instance, the MixAlco ${ }^{\mathrm{TM}}$ process has been operated in four parallel $3.78 \mathrm{~m}^{3}$ scale fed-batch fermenters processing chicken manure, urea and shredded paper to produce a mixture of carboxylate salts from processed fermentation effluent (containing approx. $6.8 \mathrm{gCOD} \mathrm{L}^{-1} \mathrm{C} 6$ ) in an 11-month time period as precursors for jet fuel and gasoline [179]. The first start-ups and university spin-offs using MMC fermentation for production of MCCA and other bio-based standard chemicals as starting to appear, such as ChainCraft B.V. in the Netherlands [180]. 
In order to increase the potential of food waste as a feedstock for production of renewable chemicals, MCCA-producing MMC fermentation can be integrated within a bio-refinery. The term bio-refinery, defined as "the sustainable processing of biomass into a spectrum of marketable products and energy", is inspired by traditional oil refineries where biomass replaces fossil fuels as feedstock for coproducing chemicals and power through various conversion technologies [181]. Process integration allows production of various compounds such as fuels, chemicals, solvents, biomaterials, food and feed ingredients, fibres and heat and power, thus increasing resilience and robustness against market price fluctuations while minimizing waste [182]. Using bio-waste as the renewable biomass feedstock, known as the 3rd generation bio-refinery concept, not only allows replacement of fossil fuel sources with a renewable alternative, but also stabilises waste streams with maximal use of resource, thus contributing to a circular economy [15]. Integration into a bio-refinery concept could include mechanical pre-treatment of waste streams to obtain pumpable mixtures, or pre-fermentation steps to obtain streams rich in lactic acid or ethanol. The combination of physical and biological processes for organic waste valorisation including MCCA will favour a myriad of product and energy goods that are market competitive (Table 7). Agler et al. gave an overview of bio-, thermo-, or electro-chemical post-processes, to convert carboxylic acids from fermentation into carbonyls, esters, alcohols or alkanes applicable as bulk fuels, solvents [26].

Table 7. Processes and applications for carboxylic acid-rich (MCCAs and VFAs) fermentation effluent currently described in literature.

\begin{tabular}{ccc}
\hline Process/Application & Product & Ref. \\
\hline MixAlco process & Alcohol fuel & {$[28]$} \\
Secondary fermentation & Lipid/biodiesel & {$[183]$} \\
Secondary fermentation & Polyhydroxyalkanoates (PHA) & {$[147,154,184]$} \\
Microbial fuel cell feedstock & Electricity & {$[185]$} \\
Carbon source for bioremediation & Dechlorination of Chloroethenes & {$[186]$} \\
Extraction and Kolbe electrolysis & Liquid alkane fuels, i.e., C10-C20 hydrocarbons & {$[14,27,95]$} \\
\hline
\end{tabular}

\section{Conclusions}

MCCAs, such as caproic and caprylic acid, are compounds of interest due to their broad range of potential applications. In contrast to chemical or single-culture biotechnological processes, using the consorted action of MMC allows to produce MCCA from complex organic feedstocks, such as food waste, in open, non-sterile systems via the natural process of chain elongation. However, the yields, concentrations and selectivity of this process must be improved in order to increase its viability. Therefore, we have summarised the current knowledge on the underlying mechanism of chain elongation by MMC, discussed the current state of the art on the use of complex organic feedstock and reviewed key operational parameters, and their interactions.

Some of the key findings lie with the fact that with complex substrates and microbial cultures, there must be a greater emphasis on managing competing reactions and positively selecting for chain elongation microbiomes. Since the microbial diversity of MMC ecosystems has been shown to be distinct from pure cultures and clean substrates, existing thermodynamic and kinetic models should be expanded to include complex feedstock and mixed cultures. Advances in microbial culture analysis, such as improved implementation of various "-omics" methods on complex samples, will boost current understanding of MMC fermentation.

Most common complex feedstocks trialled so far include residues from the bio-ethanol and dairy industries, different types of cellulosic wastes, syngas fermentation effluent and different types of organic food waste. These type of feedstocks have resulted in maximum production rates up to $8.02 \mathrm{~g}_{\mathrm{COD}} \mathrm{L}^{-1} \mathrm{~d}^{-1}$. Supplementation of complex waste-derived feedstock with chain elongation substrates such as ethanol increased production rates, with maxima reported up to $62.8 \mathrm{~g}_{\mathrm{COD}} \mathrm{L}^{-1} \mathrm{~d}^{-1}$. 
However, the negative environmental effects from chemical addition have also been reported. The use of synthetic substrates allowed production rates up to $115.2 \mathrm{~g}_{\mathrm{COD}} \mathrm{L}^{-1} \mathrm{~d}^{-1}$.

Through an extensive review of the literature, including studies targeting MCCAs or reporting MCCAs as by-products, various key operational parameters were identified and discussed to highlight the research gaps. Mesophilic temperatures are so far a preferred choice for chain elongation, yet there is little justification for this. The preferred operational $\mathrm{pH}$ seems to lie in a slight acidic range from $\mathrm{pH} 5$ to 7 , in order to limit the activity of methanogens. The relationship between organic loading rate (OLR) and MCCA production rates showed a positive correlation to some extent, however this is complicated by the degree of biodegradability of the feedstock. Linked to the organic load is the substrate-inoculum ratio $(\mathrm{F} / \mathrm{M})$ at the start-up of the process which favours the accumulation of intermediate compounds instead of methane production when $\mathrm{F} / \mathrm{M}>5$. In addition, whilst increased OLR tends to improve chain elongation, this must be coupled with sufficiently long residence times and biomass retention. OLR and retention times will have to be optimized depending on whether the reactor design has included mechanisms for biomass retention, and the biodegradability of the feedstock.

The literature study revealed very little information is available on some specific operational parameters that have been studied for other MMC applications. For example, in similar MMC fermentation processes a minimal alkalinity was beneficial to stabilise the process and reduce the need for $\mathrm{pH}$ controlling agents. However, the buffer capacity required to stimulate chain elongation has not been thoroughly investigated. The partial pressures of $\mathrm{CO}_{2}$ and $\mathrm{H}_{2}$ in the reactor headspace have been identified to influence chain elongation, however production of these gases during fermentation, and their accumulation in reactor headspace is rarely considered. In order to circumvent the antimicrobial limitations imposed by MCCAs on the microbiome, in situ extraction is often proposed, but the alternative strategies which promote the development of biofilm or granule formation, and MMC adaptation, are worthy of further research. Finally, the development of down-stream processing methods, and integration within a bio-refinery context, are crucial issues to transform MCCA production from organic waste streams into a competitive waste valorisation technology that will contribute to the development of a circular economy.

Author Contributions: Conceptualization, V.D.G., M.C. and A.L.; data curation, V.D.G.; writing-original draft preparation, V.D.G.; writing-review and editing, M.C., D.L., A.L., T.A.; supervision, A.L.; project administration, A.L.; funding acquisition, T.A.

Funding: This research was funded by the European Union's Horizon 2020 research and innovation programme under the Marie Skłodowska-Curie grant agreement H2020-MSCA-CO-FUND, No 665992, and Wessex Water and GENeco. The Centre for Sustainable Chemical Technologies is supported by EPSRC under grant EP/L016354/1.

Conflicts of Interest: The authors declare no conflict of interest.

\section{Appendix A}

Where literature values for concentration or rate are expressed in terms of mass, molarity, or carbon molarity, there were converted to $\mathrm{COD}\left(\mathrm{g}_{\mathrm{COD}} \mathrm{L}^{-1}\right.$ or $\left.\mathrm{g}_{\mathrm{COD}} \mathrm{L}^{-1} \mathrm{~d}^{-1}\right)$ according to the conversion constants given in Table A1. Where synthetic or supplemented feedstocks were employed, but overall feedstock COD was omitted, a value was estimated by summing COD concentrations of the individual compounds in the substrate. When OLR data were unreported, these were calculated by dividing feedstock COD concentration by the retention time, or by multiplying by feed flow rates, depending which values were available. Similarly, MCCA production rates are calculated via the MCCA concentration in the reactor outlet. Where retention times were un-reported, these were estimated from OLR and feedstock concentrations. Yields were calculated as the ratio of the product MCCA concentration, expressed as COD, to the COD concentration of the reactor inlet. 
Table A1. Conversion constants used to convert reported values to corresponding COD content.

\begin{tabular}{|c|c|c|c|c|c|}
\hline Compound & Acronym & Formula & MW (g mol $\left.{ }^{-1}\right)$ & Ox (-) & $\mathrm{C}(\mathrm{mol} \mathrm{C})$ \\
\hline \multicolumn{6}{|c|}{ Gas } \\
\hline Methane & $\mathrm{CH}_{4}$ & $\mathrm{CH}_{4}$ & 16 & 2.0 & 1 \\
\hline Carbon dioxide & $\mathrm{CO}_{2}$ & $\mathrm{CO}_{2}$ & 44 & 0.0 & 1 \\
\hline Hydrogen & $\mathrm{H}_{2}$ & $\mathrm{H}_{2}$ & 2 & 0.5 & 0 \\
\hline \multicolumn{6}{|c|}{ Carboxylic Acids } \\
\hline Formic acid & $\mathrm{C} 1$ & $\mathrm{CH}_{2} \mathrm{O}_{2}$ & 46 & 1.0 & 1 \\
\hline Acetic acid & $\mathrm{C} 2$ & $\mathrm{C}_{2} \mathrm{H}_{4} \mathrm{O}_{2}$ & 60 & 2.0 & 2 \\
\hline Propionic acid & $\mathrm{C} 3$ & $\mathrm{C}_{3} \mathrm{H}_{6} \mathrm{O}_{2}$ & 74 & 3.5 & 3 \\
\hline$n$-Butyric acid & $\mathrm{C} 4$ & $\mathrm{C}_{4} \mathrm{H}_{8} \mathrm{O}_{2}$ & 88 & 5.0 & 4 \\
\hline$n$-Valeric acid & $\mathrm{C} 5$ & $\mathrm{C}_{5} \mathrm{H}_{10} \mathrm{O}_{2}$ & 102 & 6.5 & 5 \\
\hline$n$-Caproic acid & C6 & $\mathrm{C}_{6} \mathrm{H}_{12} \mathrm{O}_{2}$ & 116 & 8.0 & 6 \\
\hline$n$-Heptanoic acid & $\mathrm{C} 7$ & $\mathrm{C}_{7} \mathrm{H}_{14} \mathrm{O}_{2}$ & 130 & 9.5 & 7 \\
\hline n-Caprylic acid & $\mathrm{C} 8$ & $\mathrm{C}_{8} \mathrm{H}_{16} \mathrm{O}_{2}$ & 144 & 11.0 & 8 \\
\hline$n$-Nonanoic acid & C9 & $\mathrm{C}_{9} \mathrm{H}_{18} \mathrm{O}_{2}$ & 158 & 12.5 & 9 \\
\hline \multicolumn{6}{|c|}{ Substrates } \\
\hline Lactic acid & Lact & $\mathrm{C}_{3} \mathrm{H}_{6} \mathrm{O}_{3}$ & 90 & 3.0 & 3 \\
\hline Ethanol & $\mathrm{EtOH}$ & $\mathrm{C}_{2} \mathrm{H}_{6} \mathrm{O}$ & 46 & 3.5 & 2 \\
\hline Glucose & Gluc & $\mathrm{C}_{6} \mathrm{H}_{12} \mathrm{O}_{6}$ & 180 & 6.0 & 6 \\
\hline Glycerol & Glyc & $\mathrm{C}_{3} \mathrm{H}_{8} \mathrm{O}_{3}$ & 92 & 3.5 & 3 \\
\hline Sucrose & Suc & $\mathrm{C}_{12} \mathrm{H}_{22} \mathrm{O}_{11}$ & 342 & 12.0 & 12 \\
\hline
\end{tabular}

MW: molecular weight; Ox: oxidation reaction stoichiometry; C: carbon atoms.

\section{References}

1. Eurostat the statistical office of the European Union. Recycling of Biowaste (cei_wm030); Eurostat the statistical office of the European Union: Luxembourg, 2018.

2. Appels, L.; Lauwers, J.; Degrève, J.; Helsen, L.; Lievens, B.; Willems, K.; Van Impe, J.; Dewil, R. Anaerobic digestion in global bio-energy production: Potential and research challenges. Renew. Sustain. Energy Rev. 2011, 15, 4295-4301. [CrossRef]

3. Vakalis, S.; Sotiropoulos, A.; Moustakas, K.; Malamis, D.; Vekkos, K.; Baratieri, M. Thermochemical valorization and characterization of household biowaste. J. Environ. Manag. 2017, 203, 648-654. [CrossRef] [PubMed]

4. Molino, A.; Larocca, V.; Chianese, S.; Musmarra, D. Biofuels Production by Biomass Gasification: A Review. Energies 2018, 11, 811. [CrossRef]

5. Kumar, A.; Samadder, S.R. A review on technological options of waste to energy for effective management of municipal solid waste. Waste Manag. 2017, 69, 407-422. [CrossRef] [PubMed]

6. Pham, T.P.; Kaushik, R.; Parshetti, G.K.; Mahmood, R.; Balasubramanian, R. Food waste-to-energy conversion technologies: Current status and future directions. Waste Manag. 2015, 38, 399-408. [CrossRef] [PubMed]

7. Naresh Kumar, A.; Venkata Mohan, S. Acidogenic valorization of vegetable waste for short chain carboxylic acids and biohydrogen production: Influence of pretreatment and pH. J. Clean. Prod. 2018, 203, 1055-1066. [CrossRef]

8. Sadh, P.K.; Kumar, S.; Chawla, P.; Duhan, J.S. Fermentation: A Boon for Production of Bioactive Compounds by Processing of Food Industries Wastes (By-Products). Molecules 2018, 23, 2560. [CrossRef] [PubMed]

9. Coma, M.; Martinez-Hernandez, E.; Abeln, F.; Raikova, S.; Donnelly, J.; Arnot, T.C.; Allen, M.J.; Hong, D.D.; Chuck, C.J. Organic waste as a sustainable feedstock for platform chemicals. Faraday Discuss. 2017, 202, 175-195. [CrossRef] [PubMed]

10. Tuck, C.O.; Perez, E.; Horvath, I.T.; Sheldon, R.A.; Poliakoff, M. Valorization of Biomass: Deriving more value from waste. Science 2012, 337, 695-699. [CrossRef]

11. Angenent, L.T.; Wrenn, B.A. Optimizing Mixed-Culture Bioprocessing To Convert Wastes into Bioenergy. In Bioenergy; Wall, J., Harwood, C., Demain, A., Eds.; American Society of Microbiology: Washington, DC, USA, 2008; pp. 179-194.

12. van Wyk, J.P.H. Biotechnology and the utilization of biowaste as a resource for bioproduct development. Trends Biotechnol. 2001, 19, 172-177. [CrossRef] 
13. Fava, F.; Totaro, G.; Diels, L.; Reis, M.; Duarte, J.; Carioca, O.B.; Poggi-Varaldo, H.M.; Ferreira, B.S. Biowaste biorefinery in Europe: Opportunities and research \& development needs. New Biotechnol. 2015, 32, 100-108. [CrossRef]

14. Levy, P.F.; Sanderson, J.E.; Kispert, R.G.; Wise, D.L. Biorefining of biomass to liquid fuels and organic chemicals. Enzyme Microb. Technol. 1981, 3, 207-215. [CrossRef]

15. Venkata Mohan, S.; Nikhil, G.N.; Chiranjeevi, P.; Nagendranatha Reddy, C.; Rohit, M.V.; Kumar, A.N.; Sarkar, O. Waste biorefinery models towards sustainable circular bioeconomy: Critical review and future perspectives. Bioresour. Technol. 2016, 215, 2-12. [CrossRef] [PubMed]

16. Meyer-Kohlstock, D.; Hadrich, G.; Bidlingmaier, W.; Kraft, E. The value of composting in Germany-economy, ecology, and legislation. Waste Manag. 2013, 33, 536-539. [CrossRef] [PubMed]

17. Fisgativa, H.; Tremier, A.; Le Roux, S.; Bureau, C.; Dabert, P. Understanding the anaerobic biodegradability of food waste: Relationship between the typological, biochemical and microbial characteristics. J. Environ. Manag. 2017, 188, 95-107. [CrossRef] [PubMed]

18. De Vrieze, J.; Coma, M.; Debeuckelaere, M.; Van der Meeren, P.; Rabaey, K. High salinity in molasses wastewaters shifts anaerobic digestion to carboxylate production. Water Res. 2016, 98, 293-301. [CrossRef] [PubMed]

19. Anneken, D.J.; Both, S.; Christoph, R.; Fieg, G.; Steinberner, U.; Westfechtel, A. Fatty Acids. In Ullmann's Encyclopedia of Industrial Chemistry; Wiley-VCH Verlag GmbH \& Co. KGaA: Weinheim, Germany, 2006; Volume 14, pp. 73-116.

20. Perimenis, A.; Nicolay, T.; Leclercq, M.; Gerin, P.A. Comparison of the acidogenic and methanogenic potential of agroindustrial residues. Waste Manag. 2018, 72, 178-185. [CrossRef]

21. Dahiya, S.; Kumar, A.N.; Shanthi Sravan, J.; Chatterjee, S.; Sarkar, O.; Mohan, S.V. Food waste biorefinery: Sustainable strategy for circular bioeconomy. Bioresour. Technol. 2018, 248, 2-12. [CrossRef]

22. Zacharof, M.-P.; Lovitt, R.W. Complex Effluent Streams as a Potential Source of Volatile Fatty Acids. Waste Biomass Valoriz. 2013, 4, 557-581. [CrossRef]

23. Andersen, S.J.; Candry, P.; Basadre, T.; Khor, W.C.; Roume, H.; Hernandez-Sanabria, E.; Coma, M.; Rabaey, K. Electrolytic extraction drives volatile fatty acid chain elongation through lactic acid and replaces chemical $\mathrm{pH}$ control in thin stillage fermentation. Biotechnol. Biofuels 2015, 8, 221. [CrossRef]

24. Van Immerseel, F.; Russell, J.B.; Flythe, M.D.; Gantois, I.; Timbermont, L.; Pasmans, F.; Haesebrouck, F.; Ducatelle, R. The use of organic acids to combat Salmonella in poultry: A mechanistic explanation of the efficacy. Avian Pathol. 2006, 35, 182-188. [CrossRef]

25. Solis de los Santos, F.; Donoghue, A.M.; Venkitanarayanan, K.; Metcalf, J.H.; Reyes-Herrera, I.; Dirain, M.L.; Aguiar, V.F.; Blore, P.J.; Donoghue, D.J. The natural feed additive caprylic acid decreases Campylobacter jejuni colonization in market-aged broiler chickens. Poult. Sci. 2009, 88, 61-64. [CrossRef] [PubMed]

26. Agler, M.T.; Wrenn, B.A.; Zinder, S.H.; Angenent, L.T. Waste to bioproduct conversion with undefined mixed cultures: The carboxylate platform. Trends Biotechnol. 2011, 29, 70-78. [CrossRef] [PubMed]

27. Urban, C.; Xu, J.; Sträuber, H.; dos Santos Dantas, T.R.; Mühlenberg, J.; Härtig, C.; Angenent, L.T.; Harnisch, F. Production of drop-in fuels from biomass at high selectivity by combined microbial and electrochemical conversion. Energy Environ. Sci. 2017, 10, 2231-2244. [CrossRef]

28. Holtzapple, M.T.; Davison, R.R.; Ross, M.K.; Aldrett-lee, S.; Nagwani, M.; Lee, C.M.; Lee, C.; Adelson, S.; Kaar, W.; Gaskin, D.; et al. Biomass Conversion to Mixed Alcohol Fuels using the MixAlco process. Appl. Biochem. Biotechnol. 1999, 77-79, 609-631. [CrossRef]

29. Spirito, C.M.; Richter, H.; Rabaey, K.; Stams, A.J.; Angenent, L.T. Chain elongation in anaerobic reactor microbiomes to recover resources from waste. Curr. Opin. Biotechnol. 2014, 27, 115-122. [CrossRef]

30. Weimer, P.J.; Kohn, R.A. Impacts of ruminal microorganisms on the production of fuels: How can we intercede from the outside? Appl. Microbiol. Biotechnol. 2016, 100, 3389-3398. [CrossRef] [PubMed]

31. Whipps, J.; Lewis, K.; Cooke, R. Chapter 9. Mycoparasitism and plant disease control. In Fungi in Biological Control Systems; Burge, M.N., Ed.; Manchester University Press: Manchester, UK, 1988; pp. 161-187.

32. Lahel, A.; Fanta, A.B.; Sergienko, N.; Shakya, M.; López, M.E.; Behera, S.K.; Rene, E.R.; Park, H.-S. Effect of process parameters on the bioremediation of diesel contaminated soil by mixed microbial consortia. Int. Biodeterior. Biodegradation 2016, 113, 375-385. [CrossRef]

33. Jariyal, M.; Jindal, V.; Mandal, K.; Gupta, V.K.; Singh, B. Bioremediation of organophosphorus pesticide phorate in soil by microbial consortia. Ecotoxicol. Environ. Saf. 2018, 159, 310-316. [CrossRef] 
34. Bechamp, A.; Lettre de, M.A.; Dumas, B.A.M. Gallica Bibliothèque de Météo-France; Annales de Chimie et de Physique: Paris, France, 1867.

35. Barker, H.A. The Production of Caproic and Butyric Acids by the Methane Fermentation of Ethyl Alcohol; Laboratory of Microbiology, Technical University: Delft, The Netherlands, 1937.

36. Agler, M.T.; Werner, J.J.; Iten, L.B.; Dekker, A.; Cotta, M.A.; Dien, B.S.; Angenent, L.T. Shaping reactor microbiomes to produce the fuel precursor n-butyrate from pretreated cellulosic hydrolysates. Environ. Sci. Technol. 2012, 46, 10229-10238. [CrossRef]

37. Ge, S.; Usack, J.G.; Spirito, C.M.; Angenent, L.T. Long-Term n-Caproic Acid Production from Yeast-Fermentation Beer in an Anaerobic Bioreactor with Continuous Product Extraction. Environ. Sci. Technol. 2015, 49, 8012-8021. [CrossRef] [PubMed]

38. Widder, S.; Allen, R.J.; Pfeiffer, T.; Curtis, T.P.; Wiuf, C.; Sloan, W.T.; Cordero, O.X.; Brown, S.P.; Momeni, B.; Shou, W.; et al. Challenges in microbial ecology: Building predictive understanding of community function and dynamics. ISME J. 2016, 10, 2557-2568. [CrossRef] [PubMed]

39. Kenealy, W.R.; Cao, Y.; Weimer, P.J. Production of caproic acid by cocultures of ruminal cellulolytic bacteria and Clostridium kluyveri grown on cellulose and ethanol. Appl. Microbiol. Biotechnol. 1995, 44, 507-513. [CrossRef] [PubMed]

40. Weimer, P.J.; Nerdahl, M.; Brandl, D.J. Production of medium-chain volatile fatty acids by mixed ruminal microorganisms is enhanced by ethanol in co-culture with Clostridium kluyveri. Bioresour. Technol. 2015, 175, 97-101. [CrossRef] [PubMed]

41. Leng, L.; Yang, P.; Mao, Y.; Wu, Z.; Zhang, T.; Lee, P.H. Thermodynamic and physiological study of caproate and 1,3-propanediol co-production through glycerol fermentation and fatty acids chain elongation. Water Res. 2017, 114, 200-209. [CrossRef] [PubMed]

42. Diender, M.; Stams, A.J.; Sousa, D.Z. Production of medium-chain fatty acids and higher alcohols by a synthetic co-culture grown on carbon monoxide or syngas. Biotechnol. Biofuels 2016, 9, 82. [CrossRef]

43. He, P.; Han, W.; Shao, L.; Lu, F. One-step production of C6-C8 carboxylates by mixed culture solely grown on CO. Biotechnol. Biofuels 2018, 11, 4. [CrossRef]

44. Van Eerten-Jansen, M.C.A.A.; Ter Heijne, A.; Grootscholten, T.I.M.; Steinbusch, K.J.J.; Sleutels, T.H.J.A.; Hamelers, H.V.M.; Buisman, C.J.N. Bioelectrochemical Production of Caproate and Caprylate from Acetate by Mixed Cultures. ACS Sustain. Chem. Eng. 2013, 1, 513-518. [CrossRef]

45. Vassilev, I.; Hernandez, P.A.; Batlle-Vilanova, P.; Freguia, S.; Krömer, J.O.; Keller, J.; Ledezma, P.; Virdis, B. Microbial Electrosynthesis of Isobutyric, Butyric, Caproic Acids, and Corresponding Alcohols from Carbon Dioxide. ACS Sustain. Chem. Eng. 2018, 6, 8485-8493. [CrossRef]

46. Marshall, C.W.; LaBelle, E.V.; May, H.D. Production of fuels and chemicals from waste by microbiomes. Curr. Opin. Biotechnol. 2013, 24, 391-397. [CrossRef]

47. Arslan, D.; Steinbusch, K.J.J.; Diels, L.; Hamelers, H.V.M.; Strik, D.P.B.T.B.; Buisman, C.J.N.; De Wever, H. Selective short-chain carboxylates production: A review of control mechanisms to direct mixed culture fermentations. Crit. Rev. Environ. Sci. Technol. 2016, 46, 592-634. [CrossRef]

48. Vasconcelos, E.A.F.; Leitão, R.C.; Santaella, S.T. Factors that affect bacterial ecology in hydrogen-producing anaerobic reactors. BioEnergy Res. 2016, 9, 1260-1271. [CrossRef]

49. Reddy, M.V.; ElMekawy, A.; Pant, D. Bioelectrochemical synthesis of caproate through chain elongation as a complementary technology to anaerobic digestion. Biofuels Bioprod. Biorefining 2018, 12, 966-977. [CrossRef]

50. Kleerebezem, R.; Joosse, B.; Rozendal, R.; Van Loosdrecht, M.C.M. Anaerobic digestion without biogas? Rev. Environ. Sci. Bio/Technol. 2015, 14, 787-801. [CrossRef]

51. Bastidas-Oyanedel, J.-R.; Bonk, F.; Thomsen, M.H.; Schmidt, J.E. Dark fermentation biorefinery in the present and future (bio)chemical industry. Rev. Environ. Sci. Bio/Technol. 2015, 14, 473-498. [CrossRef]

52. Braguglia, C.M.; Gallipoli, A.; Gianico, A.; Pagliaccia, P. Anaerobic bioconversion of food waste into energy: A critical review. Bioresour. Technol. 2018, 248, 37-56. [CrossRef] [PubMed]

53. Capson-Tojo, G.; Rouez, M.; Crest, M.; Steyer, J.-P.; Delgenès, J.-P.; Escudié, R. Food waste valorization via anaerobic processes: A review. Rev. Environ. Sci. Bio/Technol. 2016, 15, 499-547. [CrossRef]

54. Sen, B.; Aravind, J.; Kanmani, P.; Lay, C.-H. State of the art and future concept of food waste fermentation to bioenergy. Renew. Sustain. Energy Rev. 2016, 53, 547-557. [CrossRef] 
55. De Groof, V.; Coma, M.; Arnot, T.; Leak, D.; Lanham, A. Dataset on experimental data available in the literature on "Medium chain carboxylic acids from complex organic feedstock by mixed culture fermentation". University of Bath Research Data Archive, 2019. Available online: https://doi.org/10. 15125/BATH-00584 (accessed on 7 January 2019).

56. Seedorf, H.; Fricke, W.F.; Veith, B.; Bruggemann, H.; Liesegang, H.; Strittmatter, A.; Miethke, M.; Buckel, W.; Hinderberger, J.; Li, F.; et al. The genome of Clostridium kluyveri, a strict anaerobe with unique metabolic features. Proc. Natl. Acad. Sci. USA 2008, 105, 21128-22133. [CrossRef]

57. Kenealy, W.R.; Waselefsky, D.M. Studies on the substrate range of Clostridium kluyveri; the use of propanol and succinate. Archiv. Microbiol. 1985, 141, 187-194.

58. Angenent, L.T.; Richter, H.; Buckel, W.; Spirito, C.M.; Steinbusch, K.J.; Plugge, C.M.; Strik, D.P.; Grootscholten, T.I.; Buisman, C.J.; Hamelers, H.V. Chain Elongation with Reactor Microbiomes: Open-Culture Biotechnology To Produce Biochemicals. Environ. Sci. Technol. 2016, 50, 2796-2810. [CrossRef] [PubMed]

59. Yin, Y.; Zhang, Y.; Karakashev, D.B.; Wang, J.; Angelidaki, I. Biological caproate production by Clostridium kluyveri from ethanol and acetate as carbon sources. Bioresour. Technol. 2017, 241, 638-644. [CrossRef] [PubMed]

60. Weimer, P.J.; Stevenson, D.M. Isolation, characterization, and quantification of Clostridium kluyveri from the bovine rumen. Appl. Microbiol. Biotechnol. 2012, 94, 461-466. [CrossRef] [PubMed]

61. Thauer, R.K.; Jungermann, K.; Henninger, H.; Wenning, J.; Decker, K. The energy metabolism of Clostridium kluyveri. Eur. J. Biochem. 1968, 4, 173-180. [CrossRef] [PubMed]

62. Gildemyn, S.; Molitor, B.; Usack, J.G.; Nguyen, M.; Rabaey, K.; Angenent, L.T. Upgrading syngas fermentation effluent using Clostridium kluyveri in a continuous fermentation. Biotechnol. Biofuels 2017, 10, 83. [CrossRef] [PubMed]

63. Marounek, M.; Fliegrova, K.; Bartos, S. Metabolism and Some Characteristics of Ruminal Strains of Megasphaera elsdenii. Appl. Environ. Microbiol. 1989, 55, 1570-1573.

64. Tao, Y.; Zhu, X.; Wang, H.; Wang, Y.; Li, X.; Jin, H.; Rui, J. Complete genome sequence of Ruminococcaceae bacterium CPB6: A newly isolated culture for efficient n-caproic acid production from lactate. J. Biotechnol. 2017, 259, 91-94. [CrossRef]

65. Kim, S.G.; Jang, S.; Lim, J.H.; Jeon, B.S.; Kim, J.; Kim, K.H.; Sang, B.-I.; Jung, G.Y. Optimization of hexanoic acid production in recombinant Escherichia coli by precise flux rebalancing. Bioresour. Technol. 2018, 247, 1253-1257. [CrossRef]

66. Cheon, Y.; Kim, J.-S.; Park, J.-B.; Heo, P.; Lim, J.H.; Jung, G.Y.; Seo, J.-H.; Park, J.H.; Koo, H.M.; Cho, K.M.; et al. A biosynthetic pathway for hexanoic acid production in Kluyveromyces marxianus. J. Biotechnol. 2014, 182-183, 30-36. [CrossRef]

67. Sarria, S.; Kruyer, N.S.; Peralta-Yahya, P. Microbial synthesis of medium-chain chemicals from renewables. Nat. Biotechnol. 2017, 35, 1158-1166. [CrossRef]

68. Su, H.; Lin, J.; Tan, F. Progress and perspective of biosynthetic platform for higher-order biofuels. Renew. Sustain. Energy Rev. 2017, 80, 801-826. [CrossRef]

69. Cavalcante, W.d.A.; Leitão, R.C.; Gehring, T.A.; Angenent, L.T.; Santaella, S.T. Anaerobic fermentation for n-caproic acid production: A review. Process. Biochem. 2017, 54, 106-119. [CrossRef]

70. Steinbusch, K.J.J.; Hamelers, H.V.M.; Plugge, C.M.; Buisman, C.J.N. Biological formation of caproate and caprylate from acetate: Fuel and chemical production from low grade biomass. Energy Environ. Sci. 2011, 4, 216-224. [CrossRef]

71. Kleerebezem, R.; van Loosdrecht, M.C. Mixed culture biotechnology for bioenergy production. Curr. Opin. Biotechnol. 2007, 18, 207-212. [CrossRef] [PubMed]

72. Grootscholten, T.I.; Steinbusch, K.J.; Hamelers, H.V.; Buisman, C.J. Chain elongation of acetate and ethanol in an upflow anaerobic filter for high rate MCFA production. Bioresour. Technol. 2013, 135, 440-445. [CrossRef] [PubMed]

73. Spirito, C.M.; Marzilli, A.M.; Angenent, L.T. Higher Substrate Ratios of Ethanol to Acetate Steered Chain Elongation toward n-Caprylate in a Bioreactor with Product Extraction. Environ. Sci. Technol. 2018, 52, 13438-13447. [CrossRef] [PubMed]

74. Grootscholten, T.I.; Steinbusch, K.J.; Hamelers, H.V.; Buisman, C.J. High rate heptanoate production from propionate and ethanol using chain elongation. Bioresour. Technol. 2013, 136, 715-718. [CrossRef] 
75. Coma, M.; Vilchez-Vargas, R.; Roume, H.; Jauregui, R.; Pieper, D.H.; Rabaey, K. Product Diversity Linked to Substrate Usage in Chain Elongation by Mixed-Culture Fermentation. Environ. Sci. Technol. 2016, 50, 6467-6476. [CrossRef]

76. Chen, W.S.; Ye, Y.; Steinbusch, K.J.J.; Strik, D.P.B.T.B.; Buisman, C.J.N. Methanol as an alternative electron donor in chain elongation for butyrate and caproate formation. Biomass Bioenergy 2016, 93, 201-208. [CrossRef]

77. Kucek, L.A.; Nguyen, M.; Angenent, L.T. Conversion of L-lactate into n-caproate by a continuously fed reactor microbiome. Water Res. 2016, 93, 163-171. [CrossRef]

78. Jackson, B.E.; McInerney, M.J. Anaerobic microbial metabolism can proceed close to thermodynamic limits. Nature 2002, 415, 454-456. [CrossRef] [PubMed]

79. González-Cabaleiro, R.; Lema, J.M.; Rodríguez, J.; Kleerebezem, R. Linking thermodynamics and kinetics to assess pathway reversibility in anaerobic bioprocesses. Energy Environ. Sci. 2013, 6. [CrossRef]

80. Kleerebezem, R.; Van Loosdrecht, M.C.M. A Generalized Method for Thermodynamic State Analysis of Environmental Systems. Crit. Rev. Environ. Sci. Technol. 2010, 40, 1-54. [CrossRef]

81. Rodriguez, J.; Kleerebezem, R.; Lema, J.M.; van Loosdrecht, M.C. Modeling product formation in anaerobic mixed culture fermentations. Biotechnol. Bioeng. 2006, 93, 592-606. [CrossRef] [PubMed]

82. Hanselmann, K.W. Microbial energetics applied to waste repositories. Experientia 1991, 47, $645-687$. [CrossRef]

83. Reddy, M.V.; Mohan, S.V.; Chang, Y.C. Sustainable production of medium chain fatty acids (MCFA) with an enriched mixed bacterial culture: Microbial characterization using molecular methods. Sustain. Energy Fuels 2018, 2, 372-380. [CrossRef]

84. Chen, Y.; Cheng, J.J.; Creamer, K.S. Inhibition of anaerobic digestion process: A review. Bioresour. Technol. 2008, 99, 4044-4064. [CrossRef] [PubMed]

85. Candry, P.; Van Daele, T.; Denis, K.; Amerlinck, Y.; Andersen, S.J.; Ganigue, R.; Arends, J.B.A.; Nopens, I.; Rabaey, K. A novel high-throughput method for kinetic characterisation of anaerobic bioproduction strains, applied to Clostridium kluyveri. Sci. Rep. 2018, 8, 9724. [CrossRef]

86. Gonzalez-Cabaleiro, R.; Lema, J.M.; Rodriguez, J. Metabolic energy-based modelling explains product yielding in anaerobic mixed culture fermentations. PLoS ONE 2015, 10, e0126739. [CrossRef] [PubMed]

87. Prabhu, R.; Altman, E.; Eiteman, M.A. Lactate and acrylate metabolism by Megasphaera elsdenii under batch and steady-state conditions. Appl. Environ. Microbiol. 2012, 78, 8564-8570. [CrossRef] [PubMed]

88. Zhu, X.; Tao, Y.; Liang, C.; Li, X.; Wei, N.; Zhang, W.; Zhou, Y.; Yang, Y.; Bo, T. The synthesis of n-caproate from lactate: A new efficient process for medium-chain carboxylates production. Sci. Rep. 2015, 5, 14360. [CrossRef] [PubMed]

89. Sträuber, H.; Schröder, M.; Sabine Kleinsteuber, S. Metabolic and microbial community dynamics during the hydrolytic and acidogenic fermentation in a leach-bed process. Energy Sustain. Soc. 2012, 2, 13. [CrossRef]

90. Reddy, M.V.; Hayashi, S.; Choi, D.; Cho, H.; Chang, Y.C. Short chain and medium chain fatty acids production using food waste under non-augmented and bio-augmented conditions. J. Clean. Prod. 2018, 176, 645-653. [CrossRef]

91. Nzeteu, C.O.; Trego, A.C.; Abram, F.; O’Flaherty, V. Reproducible, high-yielding, biological caproate production from food waste using a single-phase anaerobic reactor system. Biotechnol. Biofuels 2018, 11, 108. [CrossRef] [PubMed]

92. Andersen, S.J.; De Groof, V.; Khor, W.C.; Roume, H.; Props, R.; Coma, M.; Rabaey, K. A Clostridium Group IV Species Dominates and Suppresses a Mixed Culture Fermentation by Tolerance to Medium Chain Fatty Acids Products. Front. Bioeng. Biotechnol. 2017, 5, 8. [CrossRef]

93. Agler, M.T.; Spirito, C.M.; Usack, J.G.; Werner, J.J.; Angenent, L.T. Chain elongation with reactor microbiomes: Upgrading dilute ethanol to medium-chain carboxylates. Energy Environ. Sci. 2012, 5. [CrossRef]

94. Xu, J.; Hao, J.; Guzman, J.J.L.; Spirito, C.M.; Harroff, L.A.; Angenent, L.T. Temperature-Phased Conversion of Acid Whey Waste Into Medium-Chain Carboxylic Acids via Lactic Acid: No External e-Donor. Joule 2018, 2, 280-295. [CrossRef]

95. Khor, W.C.; Andersen, S.; Vervaeren, H.; Rabaey, K. Electricity-assisted production of caproic acid from grass. Biotechnol. Biofuels 2017, 10, 180. [CrossRef] 
96. Kucek, L.A.; Spirito, C.M.; Angenent, L.T. High n-caprylate productivities and specificities from dilute ethanol and acetate: Chain elongation with microbiomes to upgrade products from syngas fermentation. Energy Environ. Sci. 2016, 9, 3482-3494. [CrossRef]

97. Kucek, L.A.; Xu, J.; Nguyen, M.; Angenent, L.T. Waste Conversion into n-Caprylate and n-Caproate: Resource Recovery from Wine Lees Using Anaerobic Reactor Microbiomes and In-line Extraction. Front. Microbiol. 2016, 7, 1892. [CrossRef]

98. Roghair, M.; Hoogstad, T.; Strik, D.; Plugge, C.M.; Timmers, P.H.A.; Weusthuis, R.A.; Bruins, M.E.; Buisman, C.J.N. Controlling Ethanol Use in Chain Elongation by CO2 Loading Rate. Environ. Sci. Technol. 2018, 52, 1496-1505. [CrossRef] [PubMed]

99. Scarborough, M.J.; Lynch, G.; Dickson, M.; McGee, M.; Donohue, T.J.; Noguera, D.R. Increasing the economic value of lignocellulosic stillage through medium-chain fatty acid production. Biotechnol. Biofuels 2018, 11, 200. [CrossRef] [PubMed]

100. Duber, A.; Jaroszynski, L.; Zagrodnik, R.; Chwialkowska, J.; Juzwa, W.; Ciesielski, S.; Oleskowicz-Popiel, P. Exploiting the real wastewater potential for resource recovery-n-caproate production from acid whey. Green Chem. 2018, 20, 3790-3803. [CrossRef]

101. Hegner, R.; Koch, C.; Riechert, V.; Harnisch, F. Microbiome-based carboxylic acids production: From serum bottles to bioreactors. RSC Adv. 2017, 7, 15362-15371. [CrossRef]

102. Liu, Y.; He, P.; Shao, L.; Zhang, H.; Lu, F. Significant enhancement by biochar of caproate production via chain elongation. Water Res. 2017, 119, 150-159. [CrossRef] [PubMed]

103. Scarborough, M.J.; Lawson, C.E.; Hamilton, J.J.; Donohue, T.J.; Noguera, D.R. Metatranscriptomic and Thermodynamic Insights into Medium-Chain Fatty Acid Production Using an Anaerobic Microbiome. mSystems 2018. [CrossRef]

104. Han, W.; He, P.; Shao, L.; Lü, F. Metabolic Interactions of a Chain Elongation Microbiome. Appl. Environ. Microbiol. 2018, 84. [CrossRef]

105. Grootscholten, T.I.; Steinbusch, K.J.; Hamelers, H.V.; Buisman, C.J. Improving medium chain fatty acid productivity using chain elongation by reducing the hydraulic retention time in an upflow anaerobic filter. Bioresour. Technol. 2013, 136, 735-738. [CrossRef]

106. Grootscholten, T.I.M.; Strik, D.P.B.T.B.; Steinbusch, K.J.J.; Buisman, C.J.N.; Hamelers, H.V.M. Two-stage medium chain fatty acid (MCFA) production from municipal solid waste and ethanol. Appl. Energy 2014, 116, 223-229. [CrossRef]

107. Lonkar, S.; Fu, Z.; Holtzapple, M. Optimum alcohol concentration for chain elongation in mixed-culture fermentation of cellulosic substrate. Biotechnol. Bioeng. 2016, 113, 2597-2604. [CrossRef]

108. Grootscholten, T.I.M.; Kinsky dal Borgo, F.; Hamelers, H.V.M.; Buisman, C.J.N. Promoting chain elongation in mixed culture acidification reactors by addition of ethanol. Biomass Bioenergy 2013, 48, 10-16. [CrossRef]

109. Chen, W.S.; Strik, D.; Buisman, C.J.N.; Kroeze, C. Production of Caproic Acid from Mixed Organic Waste: An Environmental Life Cycle Perspective. Environ. Sci. Technol. 2017, 51, 7159-7168. [CrossRef]

110. Vasudevan, D.; Richter, H.; Angenent, L.T. Upgrading dilute ethanol from syngas fermentation to n-caproate with reactor microbiomes. Bioresour. Technol. 2014, 151, 378-382. [CrossRef] [PubMed]

111. Domingos, J.M.B.; Martinez, G.A.; Scoma, A.; Fraraccio, S.; Kerckhof, F.-M.; Boon, N.; Reis, M.A.M.; Fava, F.; Bertin, L. Effect of Operational Parameters in the Continuous Anaerobic Fermentation of Cheese Whey on Titers, Yields, Productivities, and Microbial Community Structures. ACS Sustain. Chem. Eng. 2016, 5, 1400-1407. [CrossRef]

112. Tang, J.; Wang, X.C.; Hu, Y.; Zhang, Y.; Li, Y. Effect of $\mathrm{pH}$ on lactic acid production from acidogenic fermentation of food waste with different types of inocula. Bioresour. Technol. 2017, 224, 544-552. [CrossRef] [PubMed]

113. Sakai, K.; Murata, Y.; Yamazumi, H.; Tau, Y.; Mori, M.; Morjguchi, M.; Shira, Y. Selective proliferation of lactic acid bacteria and accumulation of lactic acid during open fermentation of kitchen refuse with intermittent pH adjustments. Food Sci. Technol. Resour. 2000, 6, 140-145. [CrossRef]

114. Bonk, F.; Bastidas-Oyanedel, J.R.; Yousef, A.F.; Schmidt, J.E. Exploring the selective lactic acid production from food waste in uncontrolled $\mathrm{pH}$ mixed culture fermentations using different reactor configurations. Bioresour. Technol. 2017, 238, 416-424. [CrossRef] [PubMed]

115. Wang, Y.; Mu, Y.; Yu, H. Comparative performance of two upflow anaerobic biohydrogen-producing reactors seeded with different sludges. Int. J. Hydrog. Energy 2007, 32, 1086-1094. [CrossRef] 
116. Gómez, X.; Cuetos, M.J.; Prieto, J.I.; Morán, A. Bio-hydrogen production from waste fermentation: Mixing and static conditions. Renew. Energy 2009, 34, 970-975. [CrossRef]

117. Arslan, D.; Steinbusch, K.J.; Diels, L.; De Wever, H.; Buisman, C.J.; Hamelers, H.V. Effect of hydrogen and carbon dioxide on carboxylic acids patterns in mixed culture fermentation. Bioresour. Technol. 2012, 118, 227-234. [CrossRef]

118. Chatellard, L.; Trably, E.; Carrere, H. The type of carbohydrates specifically selects microbial community structures and fermentation patterns. Bioresour. Technol. 2016, 221, 541-549. [CrossRef] [PubMed]

119. Shen, D.; Yin, J.; Yu, X.; Wang, M.; Long, Y.; Shentu, J.; Chen, T. Acidogenic fermentation characteristics of different types of protein-rich substrates in food waste to produce volatile fatty acids. Bioresour. Technol. 2017, 227, 125-132. [CrossRef] [PubMed]

120. Karthikeyan, O.P.; Mehariya, S.; Wong, J.W.C. Biorefining of food waste for fuel and energy. In Proceedings of the 4th International Conference on Energy and Environment Research (ICEER), Porto, Portugal, 17-20 July 2017.

121. Kannengiesser, J.; Sakaguchi-Soder, K.; Mrukwia, T.; Jager, J.; Schebek, L. Extraction of medium chain fatty acids from organic municipal waste and subsequent production of bio-based fuels. Waste Manag. 2016, 47, 78-83. [CrossRef] [PubMed]

122. Silva, F.C.; Serafim, L.S.; Nadais, H.; Arroja, L.; Capelaa, I. Acidogenic fermentation towards valorisation of organic waste streams into volatile fatty acids. Chem. Biochem. Eng. Q. 2013, 27, 467-476.

123. Jankowska, E.; Duber, A.; Chwialkowska, J.; Stodolny, M.; Oleskowicz-Popiel, P. Conversion of organic waste into volatile fatty acids-The influence of process operating parameters. Chem. Eng. J. 2018, 345, 395-403. [CrossRef]

124. Domke, S.B.; Aiello-Mazzarri, C.; Holtzapple, M.T. Mixed acid fermentation of paper fines and industrial biosludge. Bioresour. Technol. 2004, 91, 41-51. [CrossRef]

125. Lim, S.J.; Kim, B.J.; Jeong, C.M.; Choi, J.D.; Ahn, Y.H.; Chang, H.N. Anaerobic organic acid production of food waste in once-a-day feeding and drawing-off bioreactor. Bioresour. Technol. 2008, 99, 7866-7874. [CrossRef] [PubMed]

126. Bolaji, I.O.; Dionisi, D. Acidogenic fermentation of vegetable and salad waste for chemicals production: Effect of pH buffer and retention time. J. Environ. Chem. Eng. 2017, 5, 5933-5943. [CrossRef]

127. Ding, H.B.; Tan, G.Y.; Wang, J.Y. Caproate formation in mixed-culture fermentative hydrogen production. Bioresour. Technol. 2010, 101, 9550-9559. [CrossRef]

128. Roghair, M.; Liu, Y.; Strik, D.; Weusthuis, R.A.; Bruins, M.E.; Buisman, C.J.N. Development of an Effective Chain Elongation Process From Acidified Food Waste and Ethanol Into n-Caproate. Front. Bioeng. Biotechnol. 2018, 6, 50. [CrossRef]

129. Hollister, E.B.; Forrest, A.K.; Wilkinson, H.H.; Ebbole, D.J.; Malfatti, S.A.; Tringe, S.G.; Holtzapple, M.T.; Gentry, T.J. Structure and dynamics of the microbial communities underlying the carboxylate platform for biofuel production. Appl. Microbiol. Biotechnol. 2010, 88, 389-399. [CrossRef] [PubMed]

130. Agler, M.T.; Spirito, C.M.; Usack, J.G.; Werner, J.J.; Angenent, L.T. Development of a highly specific and productive process for $\mathrm{n}$-caproic acid production: Applying lessons from methanogenic microbiomes. Water Sci. Technol. 2014, 69, 62-68. [CrossRef] [PubMed]

131. Hollister, E.B.; Forrest, A.K.; Wilkinson, H.H.; Ebbole, D.J.; Tringe, S.G.; Malfatti, S.A.; Holtzapple, M.T.; Gentry, T.J. Mesophilic and thermophilic conditions select for unique but highly parallel microbial communities to perform carboxylate platform biomass conversion. PLoS ONE 2012, 7, e39689. [CrossRef] [PubMed]

132. Tomlinson, N.; Barker, H.A. Carbon dioxide and acetate utilization by clostridium kluyveri: I. influence of nutritional conditions on utilization patterns. J. Biol. Chem. 1953, 209, 585-595.

133. Liang, S.; Wan, C. Carboxylic acid production from brewer's spent grain via mixed culture fermentation. Bioresour. Technol. 2015, 182, 179-183. [CrossRef] [PubMed]

134. Angelidaki, I.; Sanders, W. Assessment of the anaerobic biodegradability of macropollutants. Rev. Environ. Sci. Bio/Technol. 2004, 3, 117-129. [CrossRef]

135. D'Addario, E.; Pappa, R.; Pietrangeli, B.; Valdiserri, M. The acidogenic digestion of the organic fraction of municipal solid waste for the production of liquid fuels. Water Sci. Technol. 1993, 27, 183-192. [CrossRef]

136. Maspolim, Y.; Zhou, Y.; Guo, C.; Xiao, K.; Ng, W.J. The effect of pH on solubilization of organic matter and microbial community structures in sludge fermentation. Bioresour. Technol. 2015, 190, 289-298. [CrossRef] 
137. Garcia-Aguirre, J.; Aymerich, E.; González-Mtnez de Goñi, J.; Esteban-Gutiérrez, M. Selective VFA production potential from organic waste streams: Assessing temperature and $\mathrm{pH}$ influence. Bioresour. Technol. 2017, 244, 1081-1088. [CrossRef]

138. Fisgativa, H.; Tremier, A.; Dabert, P. Characterizing the variability of food waste quality: A need for efficient valorisation through anaerobic digestion. Waste Manag. 2016, 50, 264-274. [CrossRef]

139. Zheng, M.; Zheng, M.; Wu, Y.; Ma, H.; Wang, K. Effect of $\mathrm{pH}$ on types of acidogenic fermentation of fruit and vegetable wastes. Biotechnol. Bioprocess. Eng. 2015, 20, 298-303. [CrossRef]

140. Kim, D.-H.; Kim, S.-H.; Jung, K.-W.; Kim, M.-S.; Shin, H.-S. Effect of initial pH independent of operational $\mathrm{pH}$ on hydrogen fermentation of food waste. Bioresour. Technol. 2011, 102, 8646-8652. [CrossRef] [PubMed]

141. Desbois, A.P.; Smith, V.J. Antibacterial free fatty acids: Activities, mechanisms of action and biotechnological potential. Appl. Microbiol. Biotechnol. 2010, 85, 1629-1642. [CrossRef] [PubMed]

142. Jarboe, L.R.; Royce, L.A.; Liu, P. Understanding biocatalyst inhibition by carboxylic acids. Front. Microbiol. 2013, 4, 272. [CrossRef] [PubMed]

143. Royce, L.A.; Liu, P.; Stebbins, M.J.; Hanson, B.C.; Jarboe, L.R. The damaging effects of short chain fatty acids on Escherichia coli membranes. Appl. Microbiol. Biotechnol. 2013, 97, 8317-8327. [CrossRef] [PubMed]

144. Raposo, F.; De la Rubia, M.A.; Fernández-Cegrí, V.; Borja, R. Anaerobic digestion of solid organic substrates in batch mode: An overview relating to methane yields and experimental procedures. Rene. Sustain. Energy Rev. 2012, 16, 861-877. [CrossRef]

145. Amani, T.; Nosrati, M.; Sreekrishnan, T.R. Anaerobic digestion from the viewpoint of microbiological, chemical, and operational aspects. Environ. Rev. 2010, 18, 255-278. [CrossRef]

146. Valdez-Vazquez, I.; Poggi-Varaldo, H.M. Alkalinity and high total solids affecting H2 production from organic solid waste by anaerobic consortia. Int. J. Hydrog. Energy 2009, 34, 3639-3646. [CrossRef]

147. Gameiro, T.; Lopes, M.; Marinho, R.; Vergine, P.; Nadais, H.; Capela, I. Hydrolytic-Acidogenic Fermentation of Organic Solid Waste for Volatile Fatty Acids Production at Different Solids Concentrations and Alkalinity Addition. Water Air Soil Pollut. 2016, 227. [CrossRef]

148. Vergine, P.; Sousa, F.; Lopes, M.; Silva, F.; Gameiro, T.; Nadais, H.; Capela, I. Synthetic soft drink wastewater suitability for the production of volatile fatty acids. Process. Biochem. 2015, 50, 1308-1312. [CrossRef]

149. Jiang, J.; Zhang, Y.; Li, K.; Wang, Q.; Gong, C.; Li, M. Volatile fatty acids production from food waste: Effects of $\mathrm{pH}$, temperature, and organic loading rate. Bioresour. Technol. 2013, 143, 525-530. [CrossRef] [PubMed]

150. Yuan, H.; Zhu, N. Progress in inhibition mechanisms and process control of intermediates and by-products in sewage sludge anaerobic digestion. Renew. Sustain. Energy Rev. 2016, 58, 429-438. [CrossRef]

151. Holm-Nielsen, J.B.; Oleskowicz-Popiel, P. Process control in biogas plants. In Biogas Handbook: Science Production and Application; Wellinger, A., Murphy, J.D., Baxter, D., Braun, R., Eds.; Elsevier Science \& Technology: Amsterdam, The Netherlands, 2013; Volume 52, pp. 228-247.

152. Moletta, R.; Escoffier, Y.; Ehlinger, F.; Coudert, J.; Leyris, J. On-line atuomatic control system for monitoring an anaerobic fluidized-bed reactor: Response to organic overload. Water Sci. Technol. 1995, 30, 11-20. [CrossRef]

153. Liu, G.; Zhang, R.; El-Mashad, H.M.; Dong, R. Effect of feed to inoculum ratios on biogas yields of food and green wastes. Bioresour. Technol. 2009, 100, 5103-5108. [CrossRef] [PubMed]

154. Domingos, J.M.B.; Puccio, S.; Martinez, G.A.; Amaral, N.; Reis, M.A.M.; Bandini, S.; Fava, F.; Bertin, L. Cheese whey integrated valorisation: Production, concentration and exploitation of carboxylic acids for the production of polyhydroxyalkanoates by a fed-batch culture. Chem. Eng. J. 2018, 336, 47-53. [CrossRef]

155. Xiong, B.; Richard, T.L.; Kumar, M. Integrated acidogenic digestion and carboxylic acid separation by nanofiltration membranes for the lignocellulosic carboxylate platform. J. Membrane Sci. 2015, 489, $275-283$. [CrossRef]

156. Steinbusch, K.J.; Arvaniti, E.; Hamelers, H.V.; Buisman, C.J. Selective inhibition of methanogenesis to enhance ethanol and n-butyrate production through acetate reduction in mixed culture fermentation. Bioresour. Technol. 2009, 100, 3261-3267. [CrossRef]

157. Arslan, D.; Steinbusch, K.J.; Diels, L.; De Wever, H.; Hamelers, H.V.; Buisman, C.J. Selective carboxylate production by controlling hydrogen, carbon dioxide and substrate concentrations in mixed culture fermentation. Bioresour. Technol. 2013, 136, 452-460. [CrossRef] 
158. Ren, N.-Q.; Guoa, W.-Q.; Wang, X.-J.; Xiang, W.-S.; Liua, B.-F.; Wanga, X.-Z.; Dinga, J.; Chena, Z.-B. Effects of different pretreatment methods on fermentation types and dominant bacteria for hydrogen production. Int. J. Hydrog. Energy 2008, 33, 4318-4324. [CrossRef]

159. Pendyala, B.; Chaganti, S.R.; Lalman, J.A.; Shanmugam, S.R.; Heath, D.D.; Lau, P.C.K. Pretreating mixed anaerobic communities from different sources: Correlating the hydrogen yield with hydrogenase activity and microbial diversity. Int. J. Hydrog. Energy 2012, 37, 12175-12186. [CrossRef]

160. Roghair, M.; Liu, Y.; Adiatma, J.C.; Weusthuis, R.A.; Bruins, M.E.; Buisman, C.J.N.; Strik, D. Effect of n-Caproate Concentration on Chain Elongation and Competing Processes. ACS Sustain. Chem. Eng. 2018, 6, 7499-7506. [CrossRef]

161. Jankowska, E.; Chwialkowska, J.; Stodolny, M.; Oleskowicz-Popiel, P. Effect of pH and retention time on volatile fatty acids production during mixed culture fermentation. Bioresour. Technol. 2015, 190, 274-280. [CrossRef] [PubMed]

162. Jankowska, E.; Chwialkowska, J.; Stodolny, M.; Oleskowicz-Popiel, P. Volatile fatty acids production during mixed culture fermentation-The impact of substrate complexity and pH. Chem. Eng. J. 2017, 326, 901-910. [CrossRef]

163. Amorim, N.C.S.; Amorim, E.L.C.; Kato, M.T.; Florencio, L.; Gavazza, S. The effect of methanogenesis inhibition, inoculum and substrate concentration on hydrogen and carboxylic acids production from cassava wastewater. Biodegradation 2018, 29, 41-58. [CrossRef] [PubMed]

164. Golub, K.W.; Smith, A.D.; Hollister, E.B.; Gentry, T.J.; Holtzapple, M.T. Investigation of intermittent air exposure on four-stage and one-stage anaerobic semi-continuous mixed-acid fermentations. Bioresour. Technol. 2011, 102, 5066-5075. [CrossRef] [PubMed]

165. Giovannini, G.; Donoso-Bravo, A.; Jeison, D.; Chamy, R.; Ruiz-Filippi, G.; Wouwer, A.V. A review of the role of hydrogen in past and current modelling approaches to anaerobic digestion processes. Int. J. Hydrog. Energy 2016, 41, 17713-17722. [CrossRef]

166. Harper, S.R.; Pohland, F.G. Recent developments in hydrogen management during anaerobic biological wastewater treatment. Biotechnol. Bioeng. 1986, 28, 585-602. [CrossRef] [PubMed]

167. de Kok, S.; Meijer, J.; van Loosdrecht, M.C.; Kleerebezem, R. Impact of dissolved hydrogen partial pressure on mixed culture fermentations. Appl. Microbiol. Biotechnol. 2013, 97, 2617-2625. [CrossRef] [PubMed]

168. Steinbusch, K.J.; Hamelers, H.V.; Buisman, C.J. Alcohol production through volatile fatty acids reduction with hydrogen as electron donor by mixed cultures. Water Res. 2008, 42, 4059-4066. [CrossRef]

169. Zhang, F.; Ding, J.; Zhang, Y.; Chen, M.; Ding, Z.W.; van Loosdrecht, M.C.; Zeng, R.J. Fatty acids production from hydrogen and carbon dioxide by mixed culture in the membrane biofilm reactor. Water Res. 2013, 47, 6122-6129. [CrossRef] [PubMed]

170. Venkata Mohan, S. Harnessing of biohydrogen from wastewater treatment using mixed fermentative consortia: Process evaluation towards optimization. Int. J. Hydrog. Energy 2009, 34, 7460-7474. [CrossRef]

171. Pauss, A.; Andre, G.; Perrier, M.; Guiot, S.R. Liquid-to-Gas Mass Transfer in Anaerobic Processes: Inevitable Transfer Limitations of Methane and Hydrogen in the Biomethanation Process. Appl. Environ. Microbiol. 1990, 56, 1636-1644.

172. Yesil, H.; Tugtas, A.E.; Bayrakdar, A.; Calli, B. Anaerobic fermentation of organic solid wastes: Volatile fatty acid production and separation. Water Sci. Technol. 2014, 69, 2132-2138. [CrossRef] [PubMed]

173. Roghair, M.; Strik, D.P.B.T.B.; Steinbusch, K.J.J.; Weusthuis, R.A.; Bruins, M.E.; Buisman, C.J.N. Granular sludge formation and characterization in a chain elongation process. Process. Biochem. 2016, 51, 1594-1598. [CrossRef]

174. Xu, J.; Guzman, J.J.; Andersen, S.J.; Rabaey, K.; Angenent, L.T. In-line and selective phase separation of medium-chain carboxylic acids using membrane electrolysis. Chem. Commun. 2015, 51, 6847-6850. [CrossRef] [PubMed]

175. Cordero, O.X.; Datta, M.S. Microbial interactions and community assembly at microscales. Curr. Opin. Microbiol. 2016, 31, 227-234. [CrossRef] [PubMed]

176. Choi, K.; Jeon, B.S.; Kim, B.C.; Oh, M.K.; Um, Y.; Sang, B.I. In situ biphasic extractive fermentation for hexanoic acid production from sucrose by Megasphaera elsdenii NCIMB 702410. Appl. Biochem. Biotechnol. 2013, 171, 1094-1107. [CrossRef] 
177. Jeon, B.S.; Moon, C.; Kim, B.-C.; Kim, H.; Um, Y.; Sang, B.-I. In situ extractive fermentation for the production of hexanoic acid from galactitol by Clostridium sp. BS-1. Enzyme Microb. Technol. 2013, 53, 143-151. [CrossRef] [PubMed]

178. Roddick, F.A.; Britz, M.L. Production of hexanoic acid by free and immobilised cells of Megasphaera elsdenii: Influence of in-situ product removal using ion exchange resin. J. Chem. Technol. Biotechnol. 1997, 69, 383-391. [CrossRef]

179. Taco Vasquez, S.; Dunkleman, J.; Chaudhuri, S.K.; Bond, A.; Holtzapple, M.T. Biomass conversion to hydrocarbon fuels using the MixAlco ${ }^{\mathrm{TM}}$ process at a pilot-plant scale. Biomass Bioenergy 2014, 62, 138-148. [CrossRef]

180. Chaincraft, B.V. ChainCraft: Biobased Innovators. Available online: http://www.chaincraft.eu/ (accessed on 22 September 2018).

181. de Jong, E.; Jungmeier, G. Biorefinery Concepts in Comparison to Petrochemical Refineries. In Industrial Biorefineries \& White Biotechnology; Elsevier: Amsterdam, The Netherlands, 2015; pp. 3-33.

182. Cheali, P.; Posada, J.A.; Gernaey, K.V.; Sin, G. Economic risk analysis and critical comparison of optimal biorefinery concepts. Biofuels Bioprod. Biorefining 2016, 10, 435-445. [CrossRef]

183. Park, G.W.; Fei, Q.; Jung, K.; Chang, H.N.; Kim, Y.C.; Kim, N.J.; Choi, J.D.; Kim, S.; Cho, J. Volatile fatty acids derived from waste organics provide an economical carbon source for microbial lipids/biodiesel production. Biotechnol. J. 2014, 9, 1536-1546. [CrossRef] [PubMed]

184. Amulya, K.; Jukuri, S.; Venkata Mohan, S. Sustainable multistage process for enhanced productivity of bioplastics from waste remediation through aerobic dynamic feeding strategy: Process integration for up-scaling. Bioresour. Technol. 2015, 188, 231-239. [CrossRef] [PubMed]

185. Pant, D.; Arslan, D.; Van Bogaert, G.; Gallego, Y.A.; De Wever, H.; Diels, L.; Vanbroekhoven, K. Integrated conversion of food waste diluted with sewage into volatile fatty acids through fermentation and electricity through a fuel cell. Environ. Technol. 2013, 34, 1935-1945. [CrossRef] [PubMed]

186. Lu, X.-X.; Li, G.-H.; Tao, S.; Bosma, T.; Gerritse, J. Volatile Fatty Acids as Electron Donors for the Reductive Dechlorination of Chloroethenes. J. Environ. Sci. Health Part A 2002, 37, 439-449. [CrossRef] 